\title{
Patterns and Determinants of Prescribing for Parkinson's Disease: A Systematic Literature Review
}

\author{
Khalid Orayj $\mathbb{I D}^{1,2}$ and Emma Lane $\mathbb{D D}^{1}$ \\ ${ }^{1}$ School of Pharmacy and Pharmaceutical Sciences, Cardiff University, Redwood Building, King Edward VII Ave, \\ Cardiff CF10 3NB, UK \\ ${ }^{2}$ College of Pharmacy, King Khalid University, Abha, Saudi Arabia \\ Correspondence should be addressed to Emma Lane; laneel@cardiff.ac.uk
}

Received 18 February 2019; Revised 2 October 2019; Accepted 10 October 2019; Published 3 November 2019

Academic Editor: Graziella Madeo

Copyright (C) 2019 Khalid Orayj and Emma Lane. This is an open access article distributed under the Creative Commons Attribution License, which permits unrestricted use, distribution, and reproduction in any medium, provided the original work is properly cited.

\begin{abstract}
Since the discovery of levodopa (L-dopa) in 1967, the range of medications available to treat Parkinson's disease has increased significantly and guidance on the use, efficacy, and safety of these medications has evolved. To assess levels of adherence to national prescribing guidelines and awareness of changes in the efficacy and safety data published in the profiles of medications for the treatment of $\mathrm{PD}$, we have reviewed studies on patterns and determinants of prescribing PD medications conducted in the last 50 years (since the discovery of L-dopa). A systematic literature review was conducted using EMBASE (1967 to March, 2018), Ovid MEDLINE(R) ALL (1967 to March 16, 2018), PsycINFO (1967 to the $2^{\text {nd }}$ week of March, 2018), and PubMed to identify all studies measuring prescribing patterns of PD medication between 1967 and 2017. Study design, source of data, country, year of study, number of patients and/or prescriptions, unit of analysis, prescribing determinants, and percentage utilisation of PD medications were extracted where possible. 44 studies examining prescribing patterns and/or prescribing determinants across 17 countries were identified. Unsurprisingly, L-dopa was the most commonly prescribed medication in all studies, accounting for $46.50 \%$ to $100 \%$ of all prescriptions for PD. In several studies, the prescribing rate of ergot-derived dopamine agonists (DAs) decreased over time in concordance with guidance. In contrast, the prescribing rates of non-ergot DAs increased over the last ten years in most of the included studies. In examining prescribing factors, two major categories were exemplified, patients' factors and prescribers' factors, with patients' age being the most common factor that affected the prescription in most studies. In conclusion, L-dopa is now the most commonly prescribed medication for cases of PD but there is large variation in the prescribing rates of catechol-Omethyltransferase (COMT) inhibitors, monoamine oxidase B (MAO-B) inhibitors, amantadine, and anticholinergics between countries. New studies examining the effects of recent clinical trials and measuring the prescribing rates of newly approved medications are warranted.
\end{abstract}

\section{Introduction}

Since the first detailed description of the condition now known as "Parkinson's disease" (PD) in 1817, extensive efforts have been devoted to finding a cure. In the late 1960s, George Cotzias described the efficacy and safety of oral levodopa (L-dopa) in treating the motor symptoms of Parkinson's disease. He determined that when the L-dopa dose was increased gradually, motor symptoms improved for a longer duration with minimal gastrointestinal adverse effects $[1,2]$. Other compounds were tested alongside
L-dopa, including amantadine, which Schwab et al. [3] discovered suppressed tremors. Problematically, although highly effective at treating the motor symptoms, it was determined early on that L-dopa induces dyskinesia and motor fluctuations often develop, limiting use of the drug. There remained a need to search for a drug that could improve motor symptoms without these issues and even more desirable to have disease-modifying properties $[4,5]$. In 1974 (see Figure 1), the ergot dopamine agonist, bromocriptine, was tested, demonstrating a longer half-life than L-dopa and fewer motor fluctuations [6]. One year later, a 


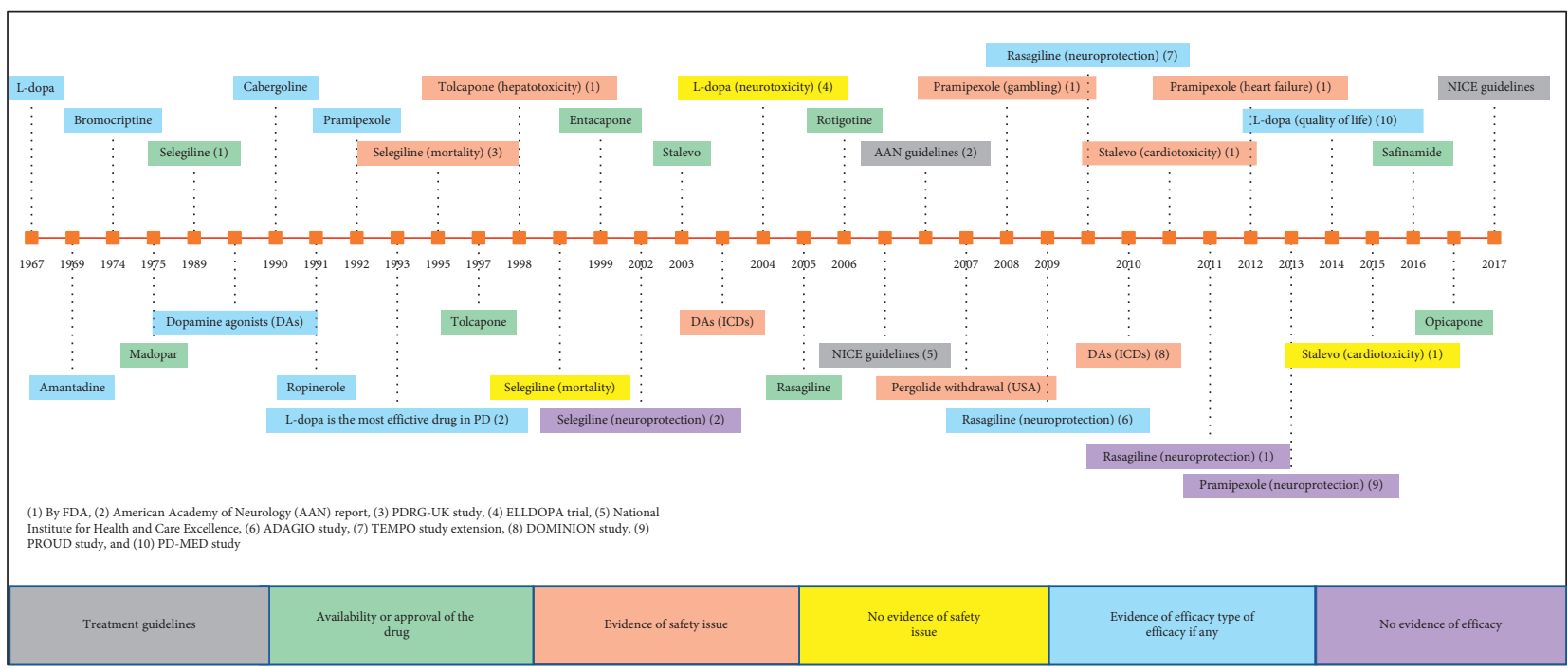

Figure 1: The evolution of pharmacotherapy for Parkinson's disease with key discoveries in efficacy, safety, and approvals of medications since the discovery of L-dopa. The horizontal line represents years from 1967 to 2017. Coloured boxes around the horizontal line represent the event type mentioned in the coloured boxes shown in the bottom of the figure.

combination of L-dopa and dopa decarboxylase inhibitor (carbidopa) reduced the gastrointestinal side effects compared to L-dopa alone [7-9]. The safety and efficacy of the monoamine oxidase B (MAO-B) inhibitor selegiline (deprenyl), as an adjunct to L-dopa therapy, was then demonstrated in 1977 [10]. From 1982 to 1992, several dopamine agonists (DAs) were introduced to the market, to be used either as L-dopa adjuncts in patients with long-term complications or as de novo therapy in place of L-dopa [11]. In 1997, tolcapone, catechol-O-methyl transferase inhibitor (COMT inhibitor) was approved in Europe as a treatment to reduce the motor fluctuations caused by L-dopa [12]. Since then, no new pharmacological class has been introduced in clinical practice; although newer generations of drugs from established drug classes have been introduced, including entacapone (COMT inhibitor) (1999), rasagiline (MAO-B inhibitor) (2005), rotigotine in a patch formulation (nonergot dopamine agonist) (2006), safinamide (MAO-B inhibitor) (2016), and opicapone (COMT inhibitor) (2016) [12-16]. Additionally, since the early 2000s, new pharmaceutical formulations such as infusion therapies (subcutaneous apomorphine and levodopa-carbidopa intestinal gel (LCIG)) became available in several countries with the promise of tackling the motor complications (mainly the wearing-off phenomenon) caused by the oral form of L-dopa in patients with advanced stage of PD [17].

The perception of the utility of these drugs has evolved over time and this is reflected in subtle changes in the guidance; for example, DAs and MAO-B inhibitors were initially purported to have potential neuroprotective properties leading to their early prescribing following diagnosis but several clinical trials failed to find clear evidence to support this [18-23]. L-DOPA has been widely compared with the DAs, including bromocriptine, ropinirole, pramipexole, and pergolide; these concluded that initiating therapy with DAs was associated with delaying dyskinesia onset or motor fluctuations or both [24-28]. Accordingly, guidelines recommended starting therapy with DAs rather than L-dopa, unless the DAs failed to manage the motor symptoms [29-31] or alternatively commencing therapy with L-dopa or DAs without preference [30, 32]. The impact of the motor fluctuations caused by L-dopa on patients' quality of life (QoL) was not clear until 2014 when the PDMED study [33] used the quality of life (QoL) scale as a primary outcome. The study's main finding was that early initiation of L-dopa resulted in a better QoL in the long term than initiating DAs and MAO-B inhibitors [33].

Increased knowledge of efficacy and safety and growing number of drugs in the market would be expected to impact prescribing decisions and drug utilisation rates of $\mathrm{PD}$ medications. One means through which adherence to national prescribing guidelines and awareness of the changes in efficacy and safety in the medications' profiles can be evaluated by examining prescribing patterns. Doing so would help determine the factors that affect prescribing, including factors such as sex, age, socioeconomic status, education, and drug pricing [34]. Various studies have been conducted worldwide and this review draws together prescribing patterns and determinates of PD medication utilisation across the globe to examine the extent to which these patterns accord with the changes occurring in the safety and efficacy profiles of PD medications.

\section{Methods}

2.1. Search Strategy. A comprehensive and systematic literature search was conducted using EMBASE (1947-March, 2018), Ovid MEDLINE(R) ALL (1946 to March 16, 2018), PsycINFO (1806 to the $2^{\text {nd }}$ week of March, 2018), and PubMed to identify all studies measuring prescribing patterns of PD medications (Figure 2). The key words used were "drug utilization" or "prescribing pattern" or 


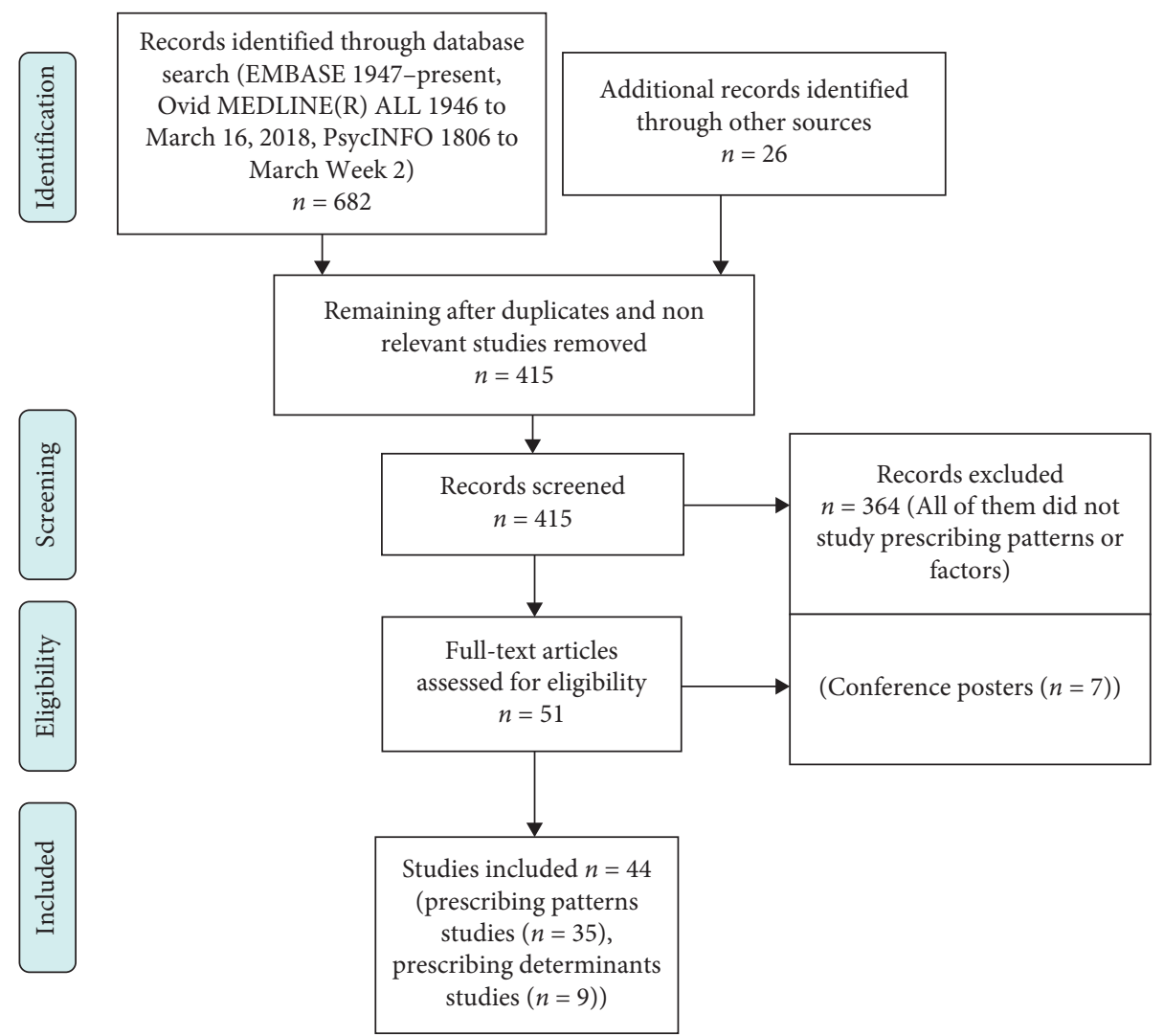

FIGURE 2: PRISMA flow chart for systematic research of prescribing patterns and determinants study.

"pharmacoepidemiology" or "prescribing trend" or "inappropriate prescribing" or "prescribing factors" or "prescribing determinants" or "prescribing behaviour," combined with "Parkinson's disease" or "idiopathic Parkinson's disease" or "Primary Parkinsonism" or "Paralysis Agitans" or "Antiparkinson drugs" or "Antiparkinsonians" or "Antiparkinsonian agents" or "Levodopa" or "L-dopa" or "dopamine agonists" or "apomorphine" or "cabergoline" or "lisuride" or "pergolide" or "pramipexole" or "ropinirole" or "rotigotine" or "amantadine" or "Catechol O-Methyltransferase Inhibitors" or "entacapone" or "tolcapone" or "Monoamine Oxidase Inhibitors" or "rasagiline" or "selegiline" or "anticholinergics or "orphenadrine" or "procyclidine" or "trihexyphenidyl." Manual reference research and Google Scholar were also used in the review (see Part 1 in Supplementary Materials).

2.2. Inclusion and Exclusion Criteria. All English-language studies that measured the prescribing pattern and/or prescribing and drug utilisation determinants of one or more than one class of PD medication at any time point were included in the review. Since the purpose of this review was to examine all prescribing patterns and determinants studies, the only exclusion criterion was if the study was published only as a conference poster. Non-English-language studies were excluded from both the main analysis and the quality assessment due to the lack of translation resources; however, when possible, the English abstracts of these studies were screened and obtained (see Parts 2 and 3 in Supplementary Materials).

2.3. Data Extraction, Quality Assessment Checklist, and Data Analysis. Where information was available, the following data were extracted from each study: study design, source of data, country, year of study, number of patients and/or prescriptions, unit of analysis, prescribing determinants, main findings, and utilisation percentages of PD medications. The selected studies were classified into two categories: studies that examined the prescribing patterns of $\mathrm{PD}$ medications with or without prescribing determinants and studies that examined prescribing determinants without measuring prescribing patterns of PD medications.

The studies selected for this review had heterogeneous designs which made it difficult to apply the commonly used quality and reporting assessment checklists for cross-sectional observational studies such as the STROPE checklist [35] and the National Institutes of Health Quality Assessment Tool for Observational Cohort and Cross-Sectional Studies [36]. Most published quality and reporting assessment checklists have not been designed to be applied to pharmacoepidemiological and drug utilisation studies [37]. All the studies selected in this review were descriptive in nature and did not measure outcomes caused by exposure in the study participants. For this reason, and to assess and critique the quality of the selected studies, a critical appraisal tool that addresses prevalence studies was used [38]. This 
tool was chosen as the drug utilisation prevalence of PD medications is the primary interest of this review. The prevalence of $\mathrm{PD}$ medication use was used to estimate the prevalence of PD itself in several studies [39, 40]; however, in the current review, it was used solely to study the prescribing patterns and trends of PD medications. For the purposes of this review "The Joanna Briggs Institute Critical Appraisal Tool for Use in Prevalence Studies" was used (see Part 4 in Supplementary Materials). This tool poses 10 questions which can be answered by yes, no, unclear, or not applicable. The questions relate to the sample representativeness of the target population, the study participants recruiting method, the sample size adequacy, the detailed description of study subjects, the sufficiency of the coverage of the selected sample during analysis, the objectivity of the criteria used in measuring the condition, the reliability of the criteria used to measure the condition, the appropriateness of the statistical analysis considering potential confounding factors, and finally, the objectivity of the criteria used to identify subpopulations [38].

After obtaining quality score of each study, the Kruskal-Wallis test was used to compare the prescribing rates at different tiers of quality scores (for this purpose only, quality scores were classified into three tiers: from 1 to 3 and 4 to $6,>6$ ). Additionally, a Kruskal-Wallis test also was used to compare the prescribing rates according to the source of data. The significance level was set at $P<0.05$ in both tests.

\section{Results}

3.1. Search Results and Characteristics of the Drug Utilisation Studies. The initial search of the databases used in this review resulted in the retrieval of 682 studies (see Part 1 in Supplementary Materials). Twenty-six additional studies were identified through other sources (manual reference research and Google Scholar). After removing duplicated and nonrelevant studies, 415 studies remained. The abstracts of these 415 studies were screened and this resulted in the removal of 364 studies which did not examine prescribing patterns or determinants, thus leaving 51 studies. A further 7 studies were excluded as they were published only as conference posters. In total, therefore, 44 studies remained that examined the prescribing pattern and determinants in 17 countries and these were included in this review (Figure 2) [41-84]. Of the 44 studies, $40 \%(n=18)$ were undertaken in Europe (Italy $(n=4)$, England $(n=2)$, Germany $(n=2)$, Spain $(n=2)$, Sweden $(n=3)$, Norway $(n=2)$, whole Europe $(n=1)$, Finland $(n=1)$, France $(n=1)$, and UK $(n=1)) ; 29 \%$ $(n=13)$ were undertaken in the USA; $25 \%(n=11)$ were undertaken in Asia (Japan $(n=4)$, India $(n=3)$, Taiwan $(n=2)$, and China $(n=1))$, and $7 \%(n=3)$ were undertaken in other countries (Australia $(n=1)$, New Zealand $(n=1)$, and South Africa $(n=1))$. Two studies were conducted in two different countries at once ((USA and Japan jointly) [59] and (Sweden and Norway jointly [84])). This explains why the total of the percentages quoted above exceeds $100 \%$ (see Tables 1 and 2). The results of the Kruskal-Wallis tests indicated no significant differences between prescribing rates of PD medications across different levels of study quality scores and across the several data sources that were used in the studies (see Table 3 and Part 5 in Supplementary Materials). The only exception was L-dopa which was prescribed significantly more in studies which used patients' interviews, questionnaires, or surveys compared with studies which used insurance-claims, prescription registries, or drug sales databases $(P$ value $=0.011)$ (Table 3$)$.

Of the 44 studies, 35 were designed to examine the prescribing pattern of $\mathrm{PD}$ medications with or without measuring prescribing determinants (Table 1) [41-48, 50, 51, $53-75,83,84]$ and 9 studies measured the prescribing determinants and utilisation factors without measuring prescription rates of PD medications (Table 2) [49, 52, 76-82]. The sources of data varied according to each study design; insurance-claims, prescription registries, or drug sales databases in 16 studies [ $45-47,53,54,56-58,61,62,64,65,72$, $75,81,83]$; medical charts and administrative databases in 13 studies [41-43, 48, 50, 51, 66-70, 79, 82]; patients' interviews, questionnaires, or surveys in 12 studies [ $44,55,59,60,63,71$, $73,74,76-78,84]$; and finally, 3 studies were designed as post hoc studies that used previously conducted clinical trials to find the prescribing patterns and determinates of PD medications (see Tables 1 and 2) $[49,52,80]$. The timeframe of the studies that were reviewed was from 1986 to 2017. Out of the studies that examined prescribing patterns, 19 were cross sectional in design and calculated the prescription rates of PD medications in a particular period without comparing the rates with other periods $[41-45,48,50,55,57,60,64,68$, $69,71,73-75,83,84]$ and 15 were designed to compare the prescribing patterns in two or more different periods $[46,47$, $51,53,54,56,58,59,61-63,65-67,72]$. In one study that was conducted in Singapore, the year of the study was not possible to establish [70]. Study settings in prescribing pattern studies varied and included a community setting only $(n=20)[42-44,46,47,55,57,59,62,63,65-71,73,75$, $84]$, inpatient and community settings $(n=9)[45,50,54,56$, $58,60,61,72,74]$, inpatient setting only $(n=2)[41,51]$, community and care home settings $(n=2)[48,53]$, inpatient, community, and care home settings $(n=1)$ [64], and finally, care home setting only $(n=1)$ [83]. The general characteristics of the drug prescribing studies that were reviewed are summarised in Table 1 . In the prescribing pattern studies, number of patients treated per 100,000 inhabitants, number of prescriptions, number of patients prescribed a particular medication, defined daily doses (DDD) per 1000 inhabitants per day (DID), and number of person-years were used as units of analysis in all studies except one study conducted in England that used drug sales as a unit of analysis [58]. In the studies that used the number of patients prescribed a particular medication $[41-43,45,47$, $48,51,54,55,59-61,66,68-71,73-75,83,84]$ or the number of person-years [64] as units of analysis, the total prescription rates of all PD medications may not add up to $100 \%$ due to the possibility that the patients were prescribed combination therapy. On the contrary, the studies that used the number of prescriptions or DID as units of analysis [53, $57,62,65,67,72]$, the total prescription rates of all PD medications may not add up to $100 \%$ due to rounding off to the nearest percent or due to the inability to calculate some 


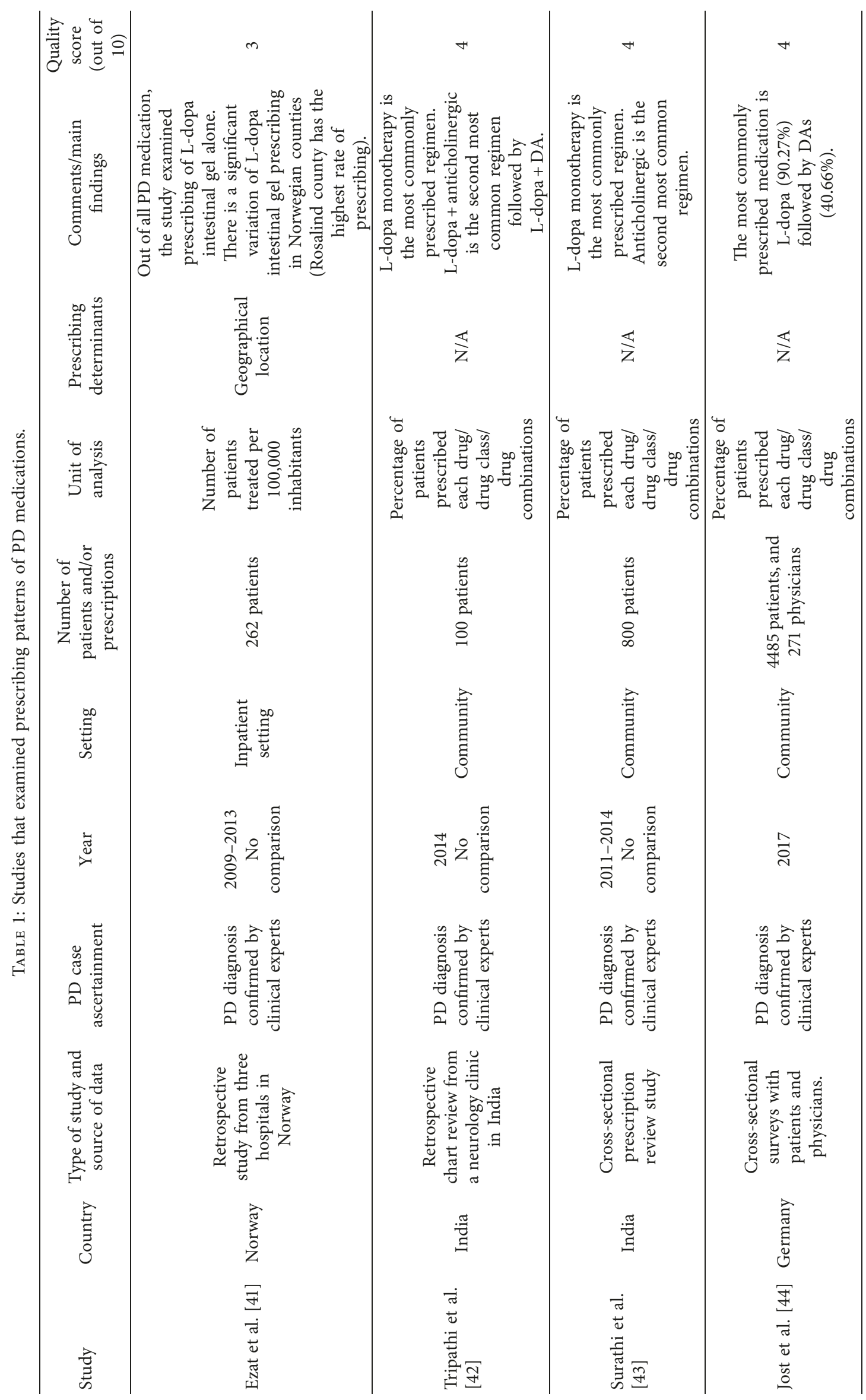




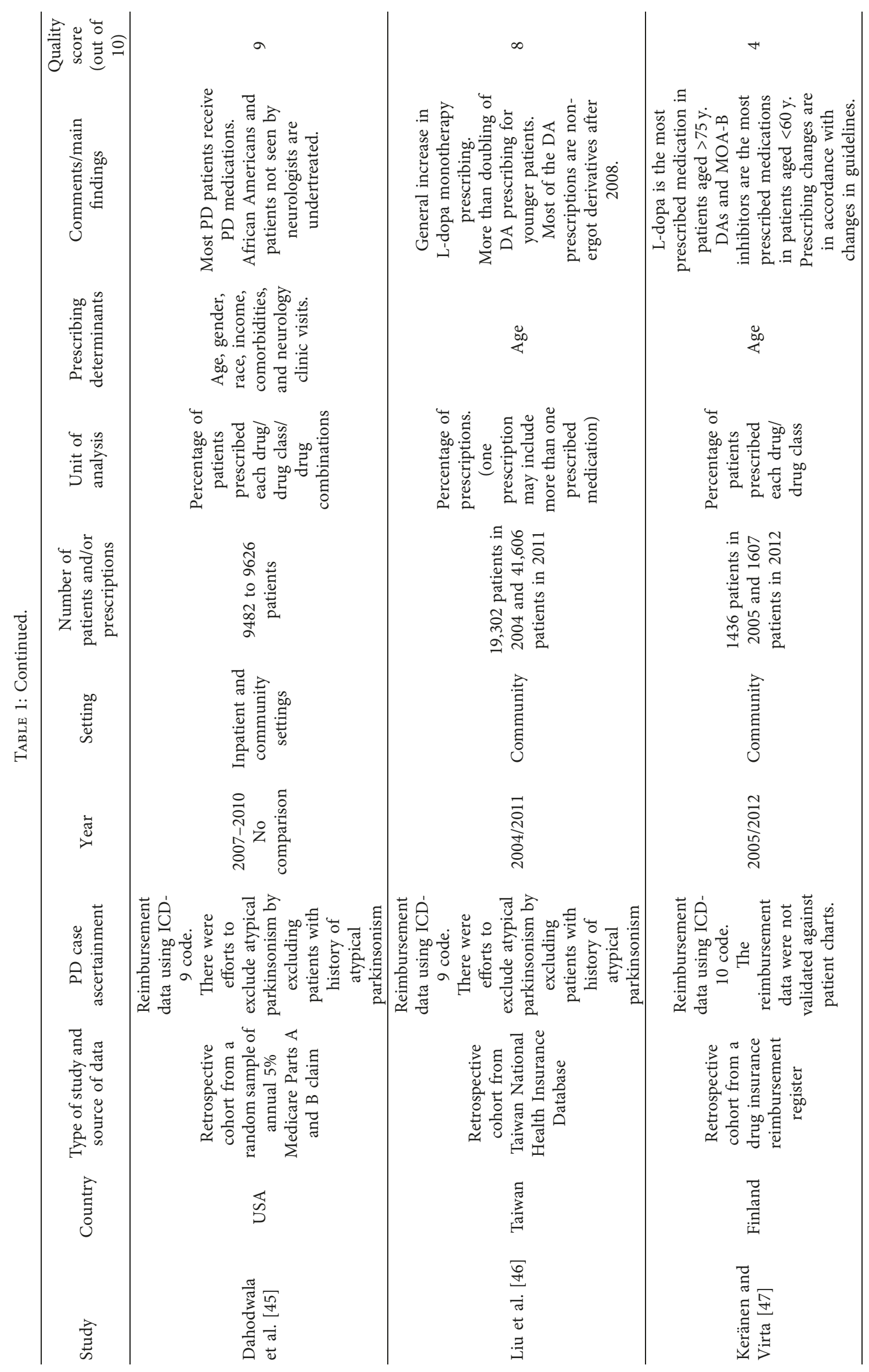




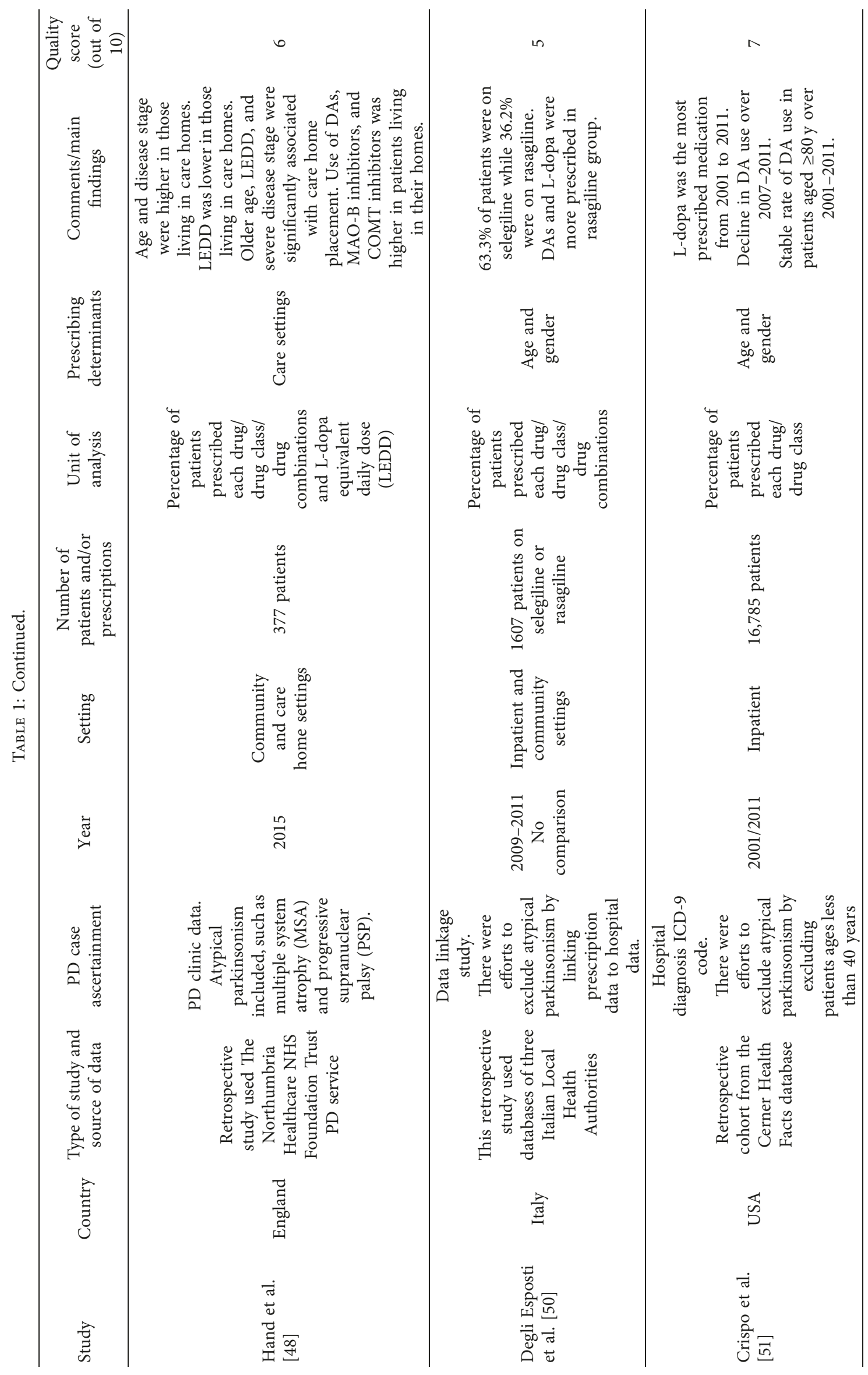




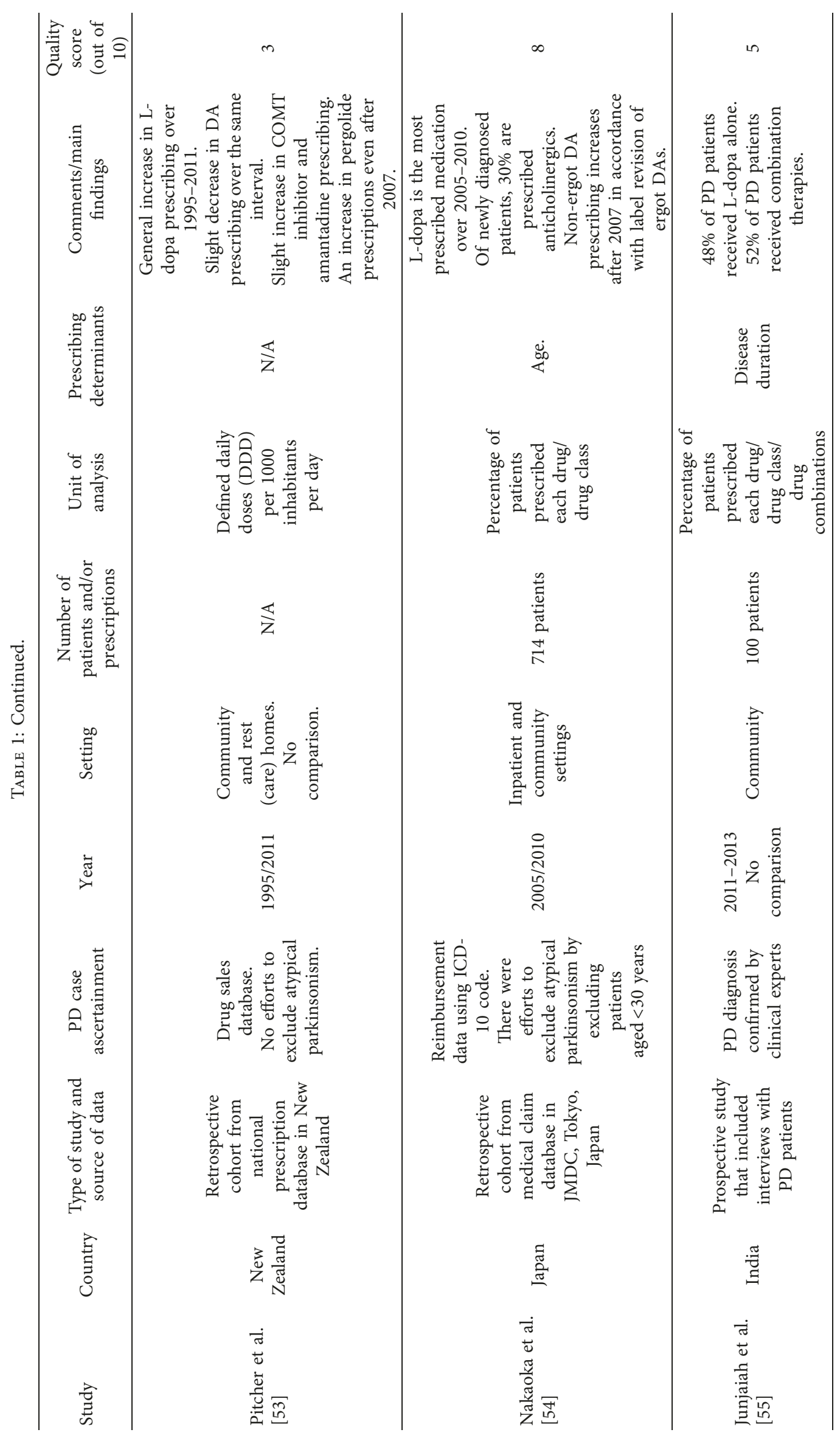




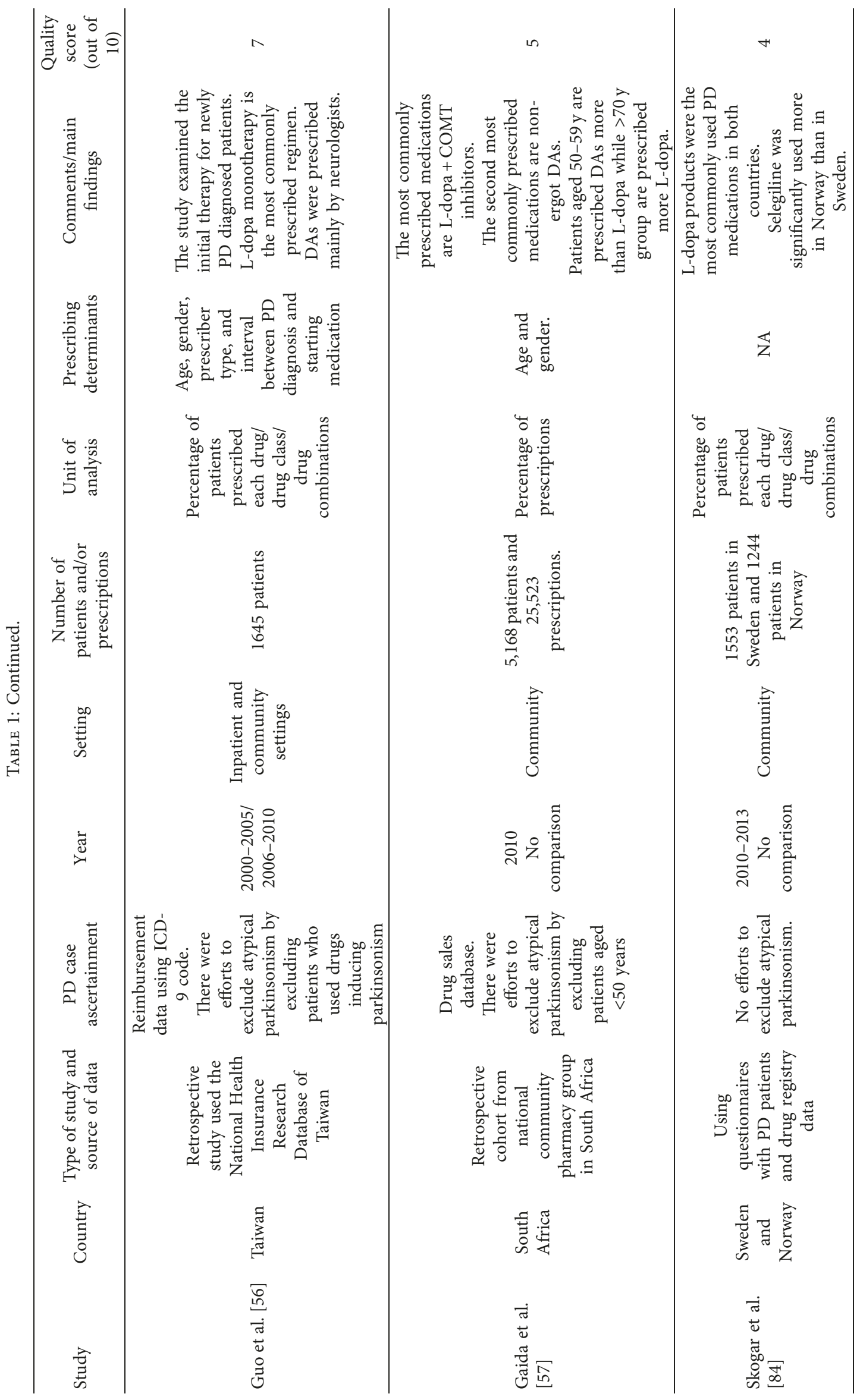




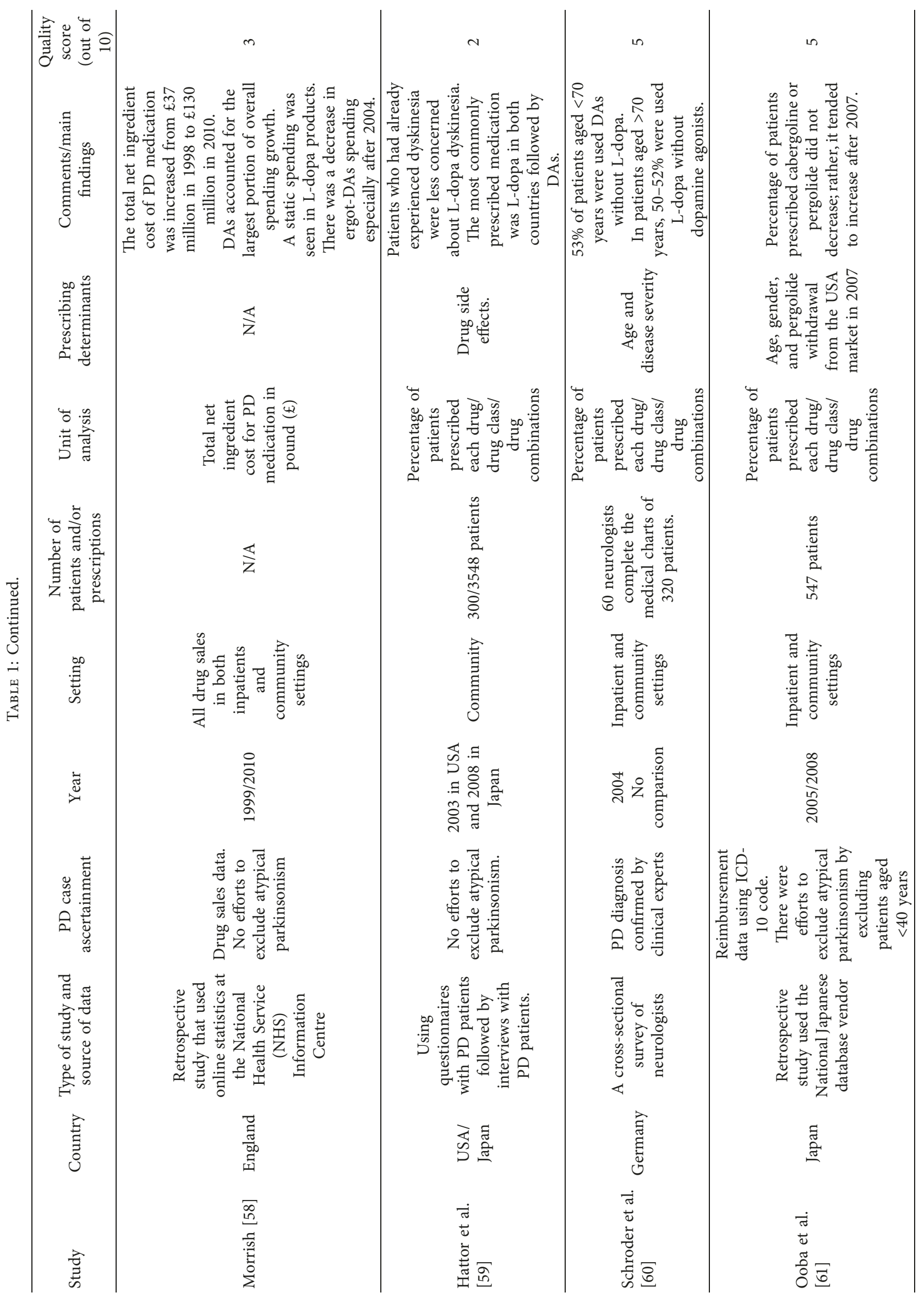




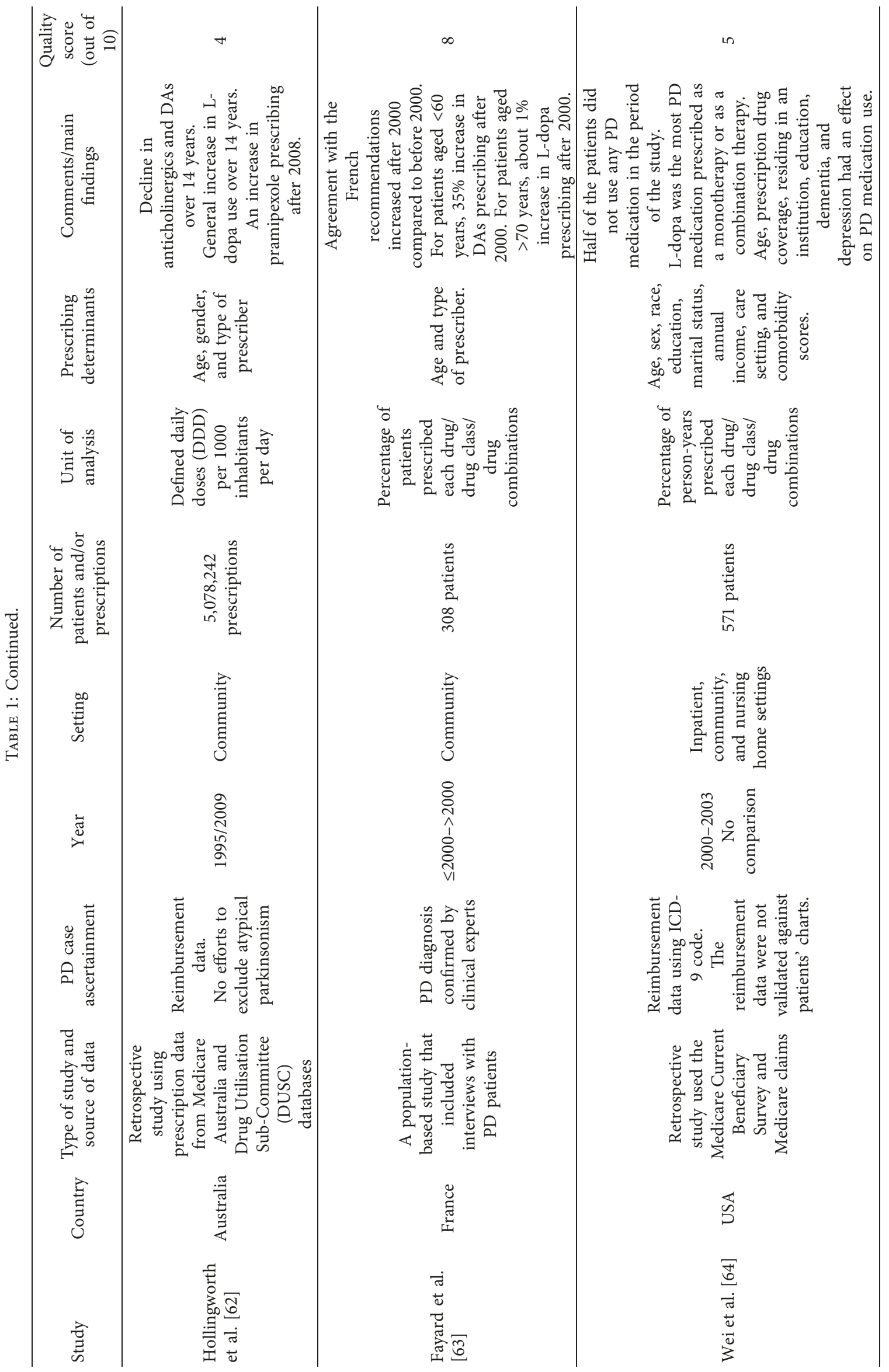




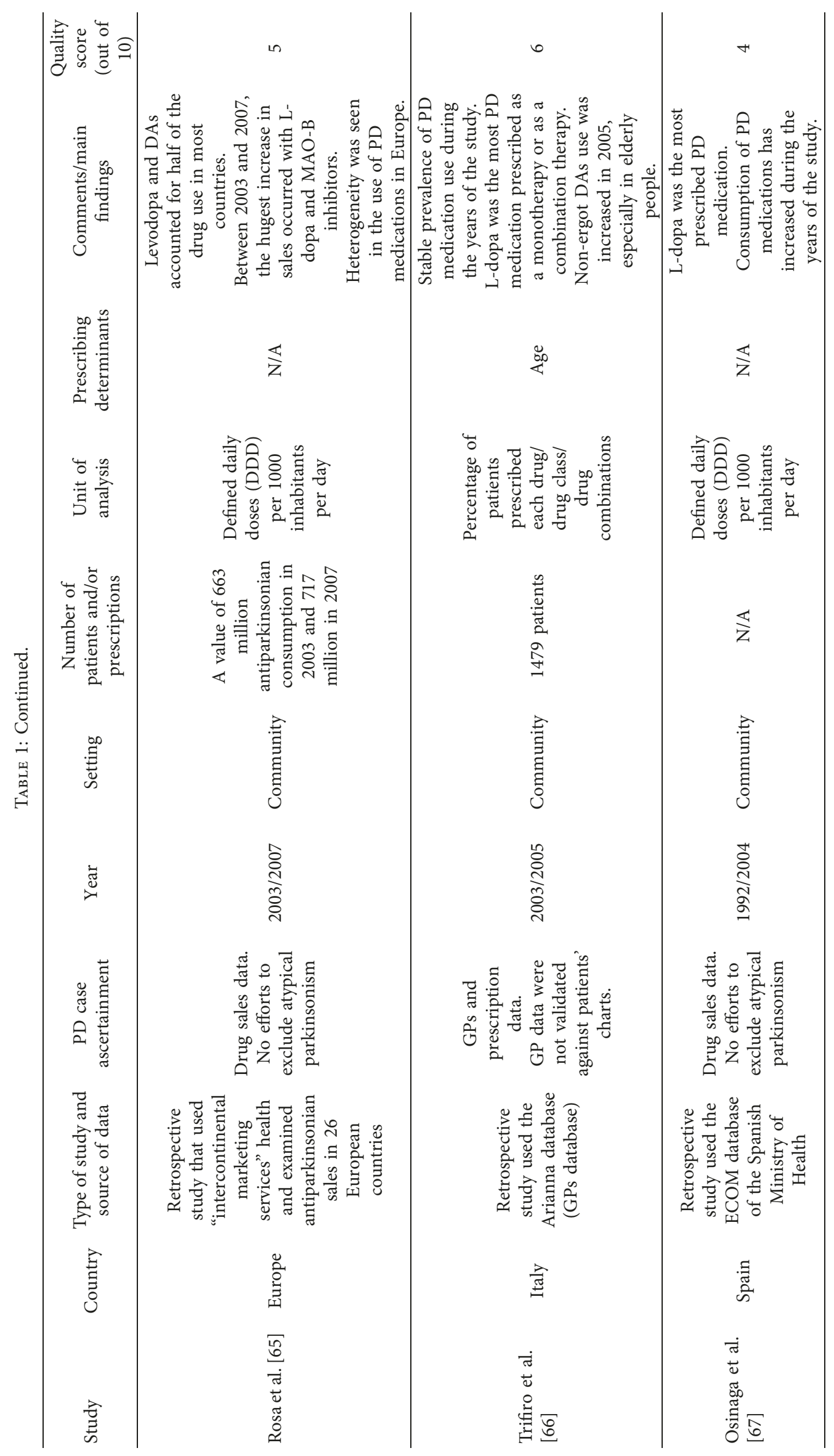




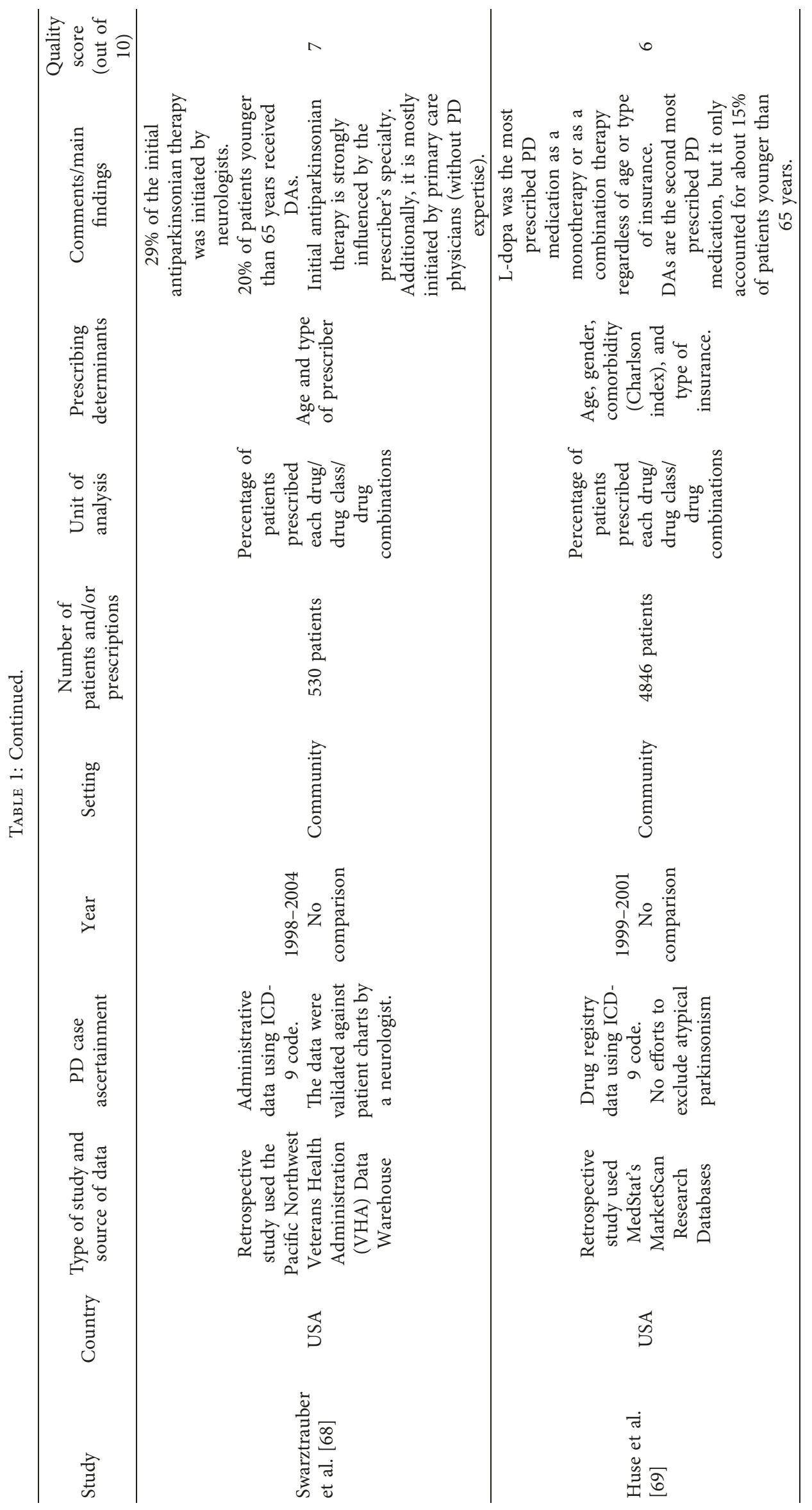




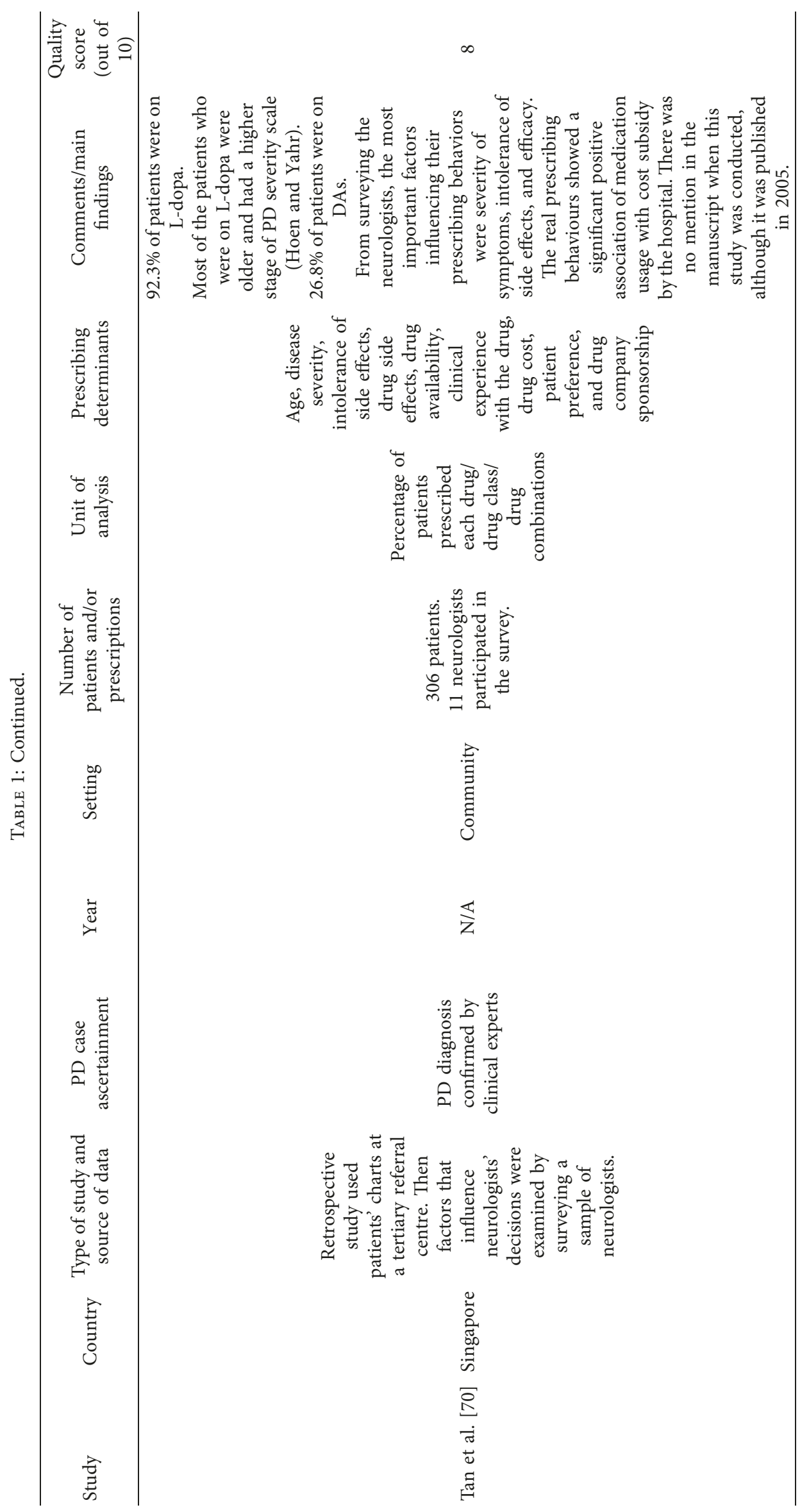




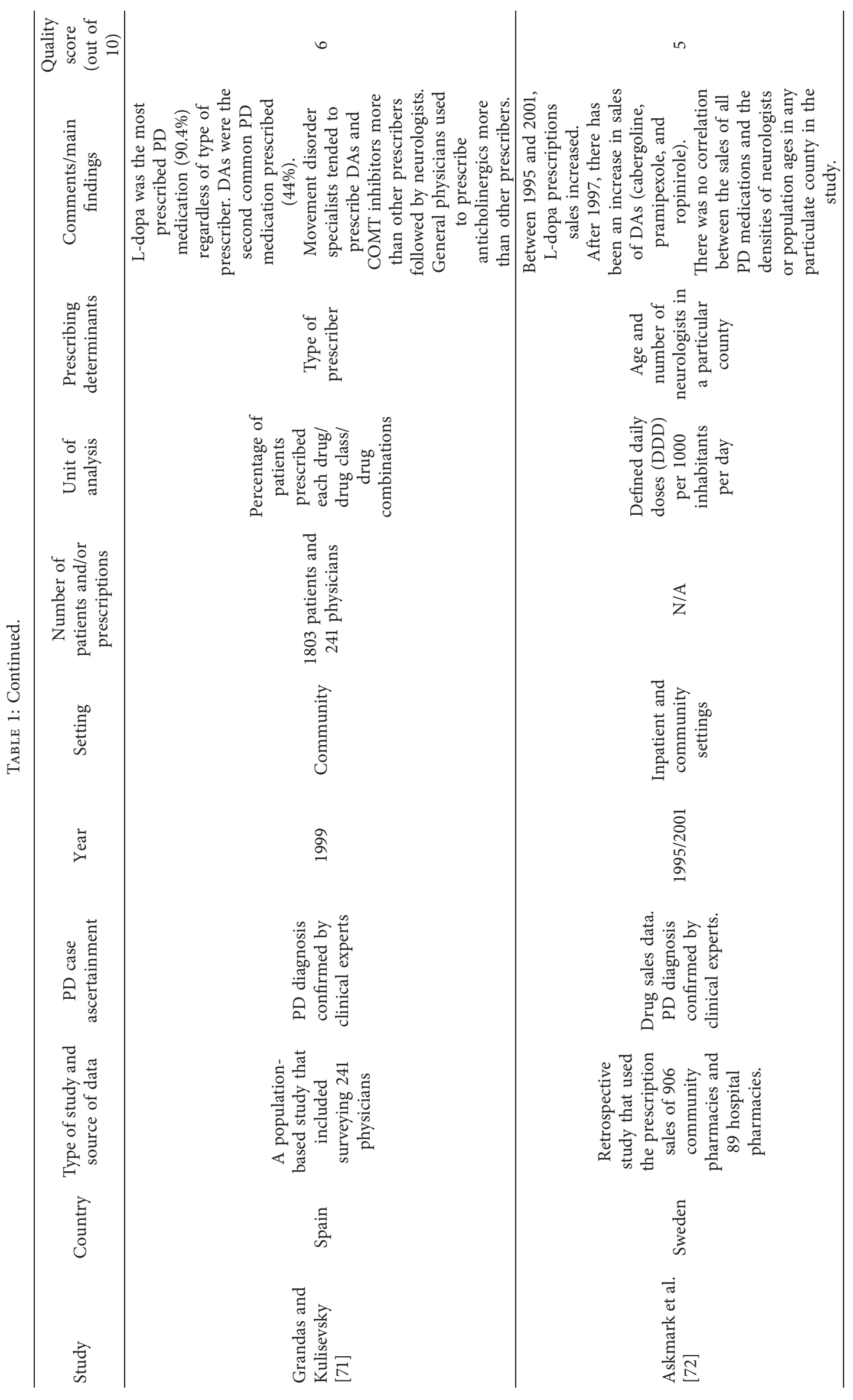




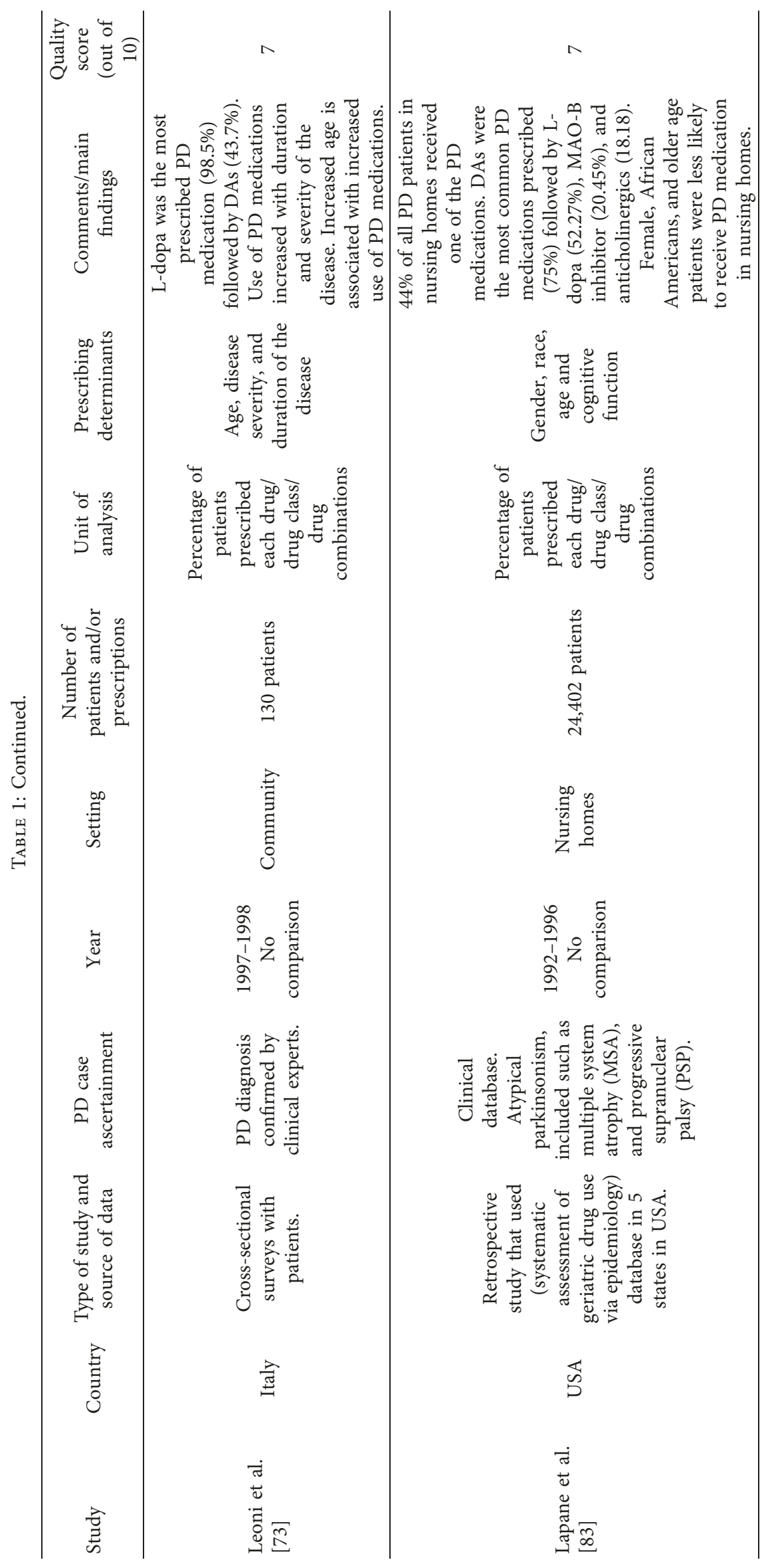




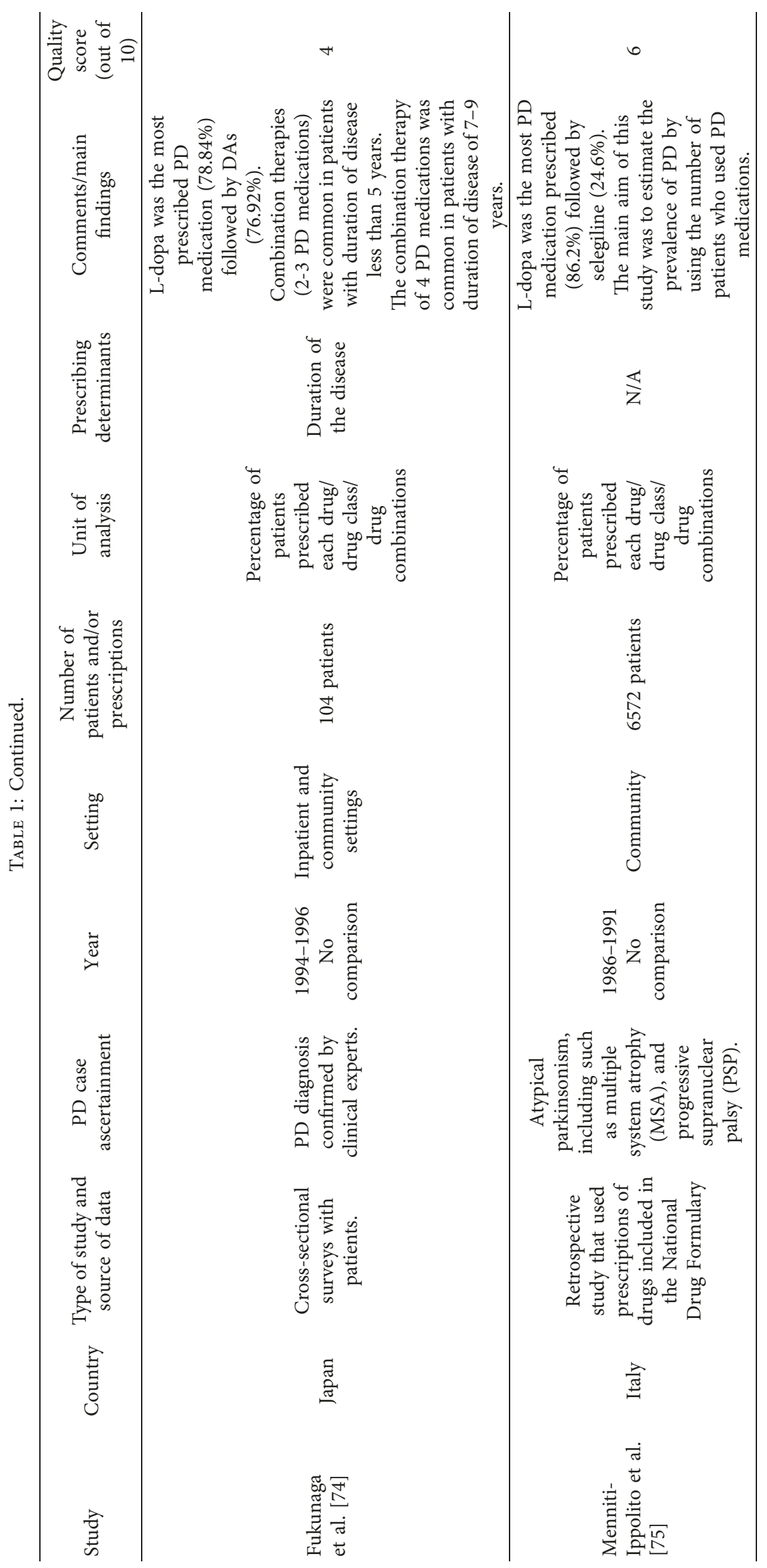




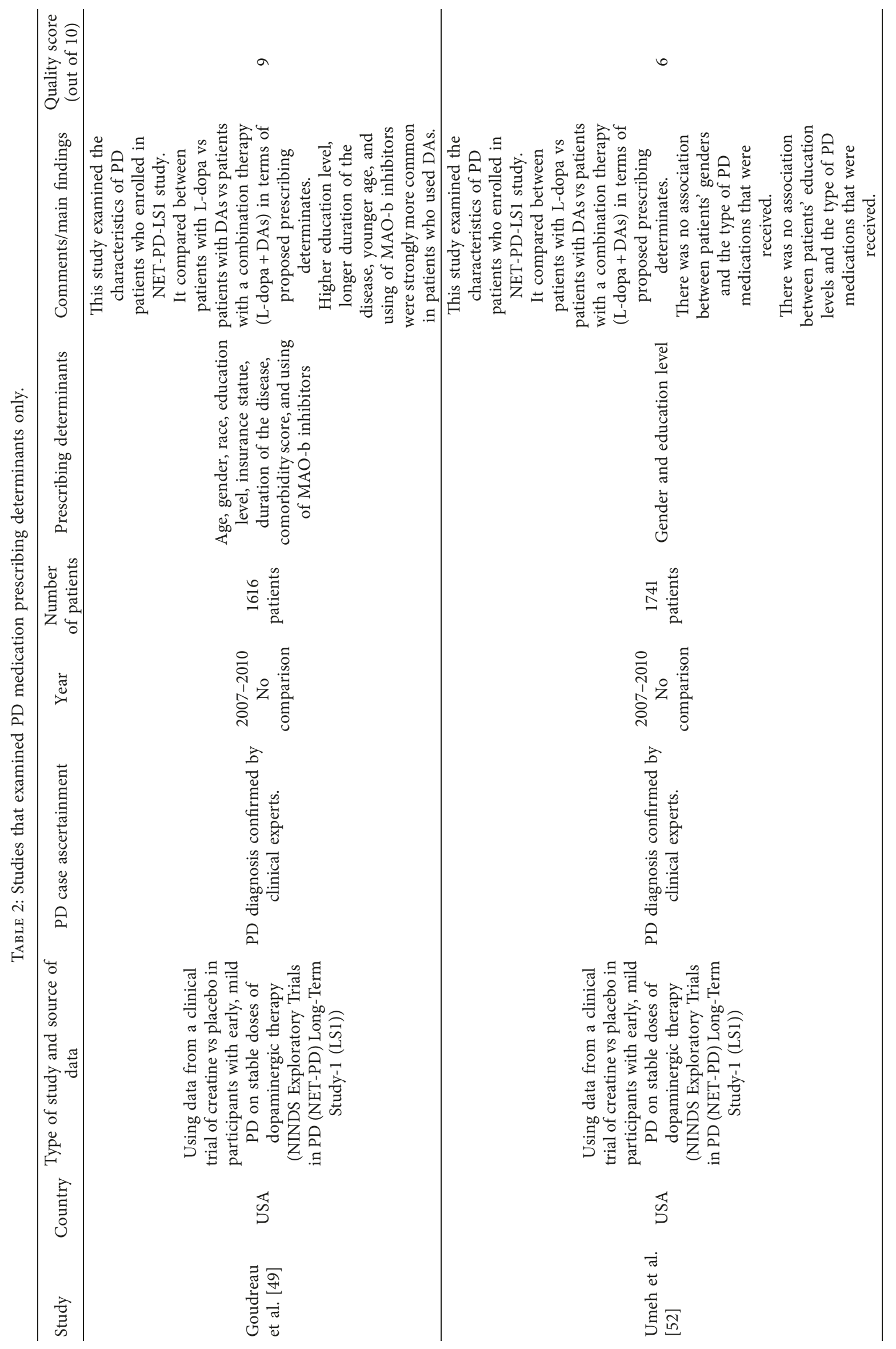




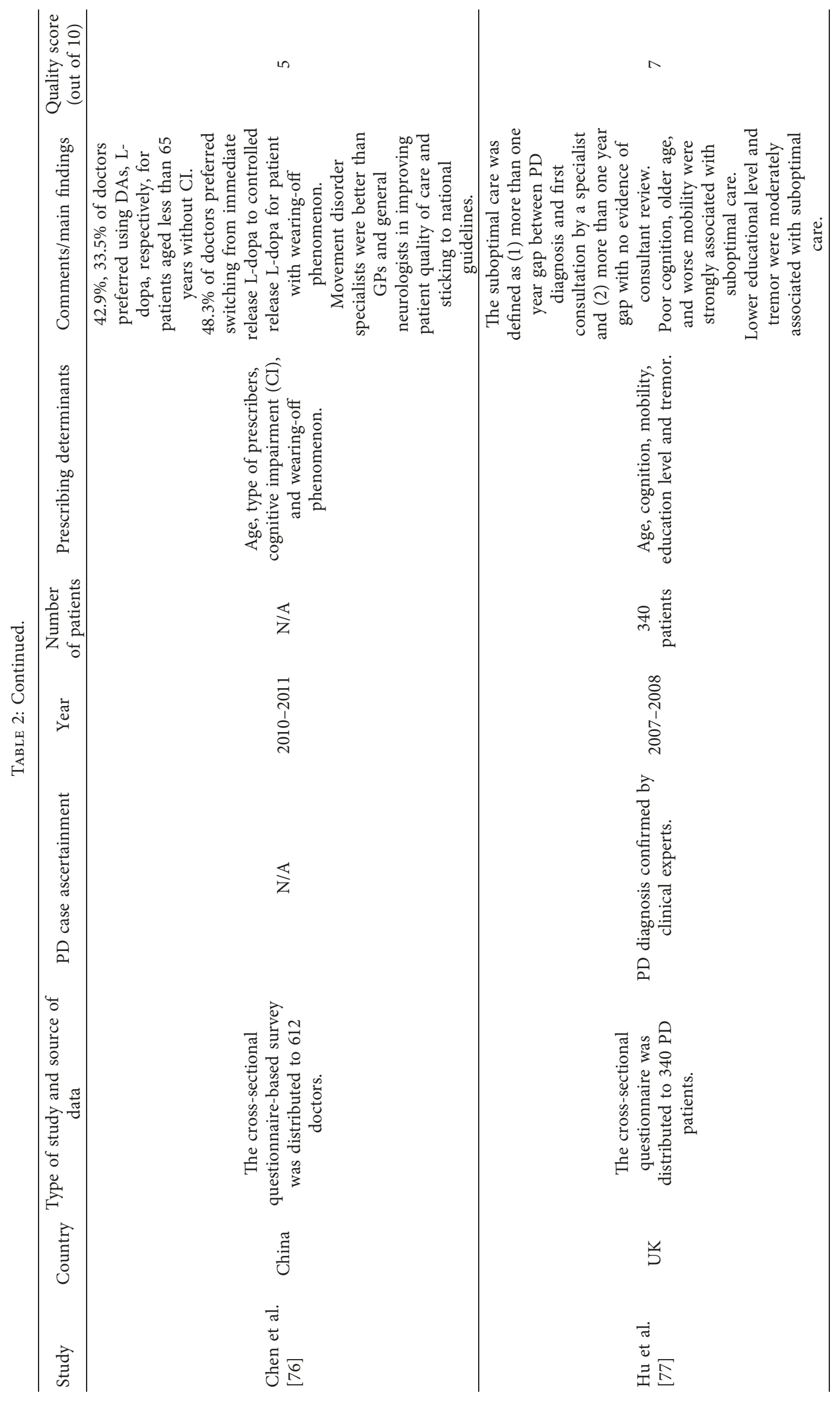




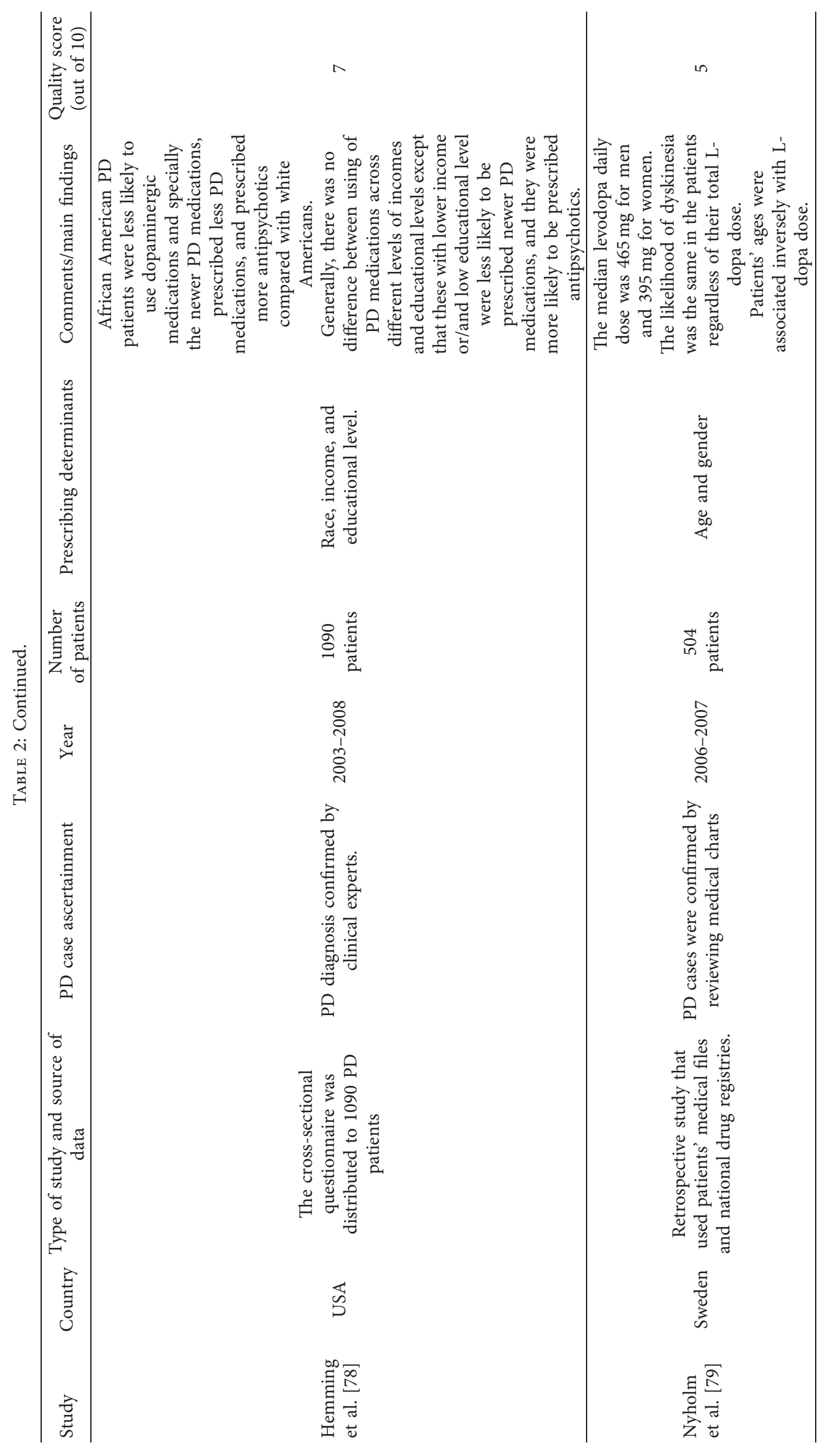




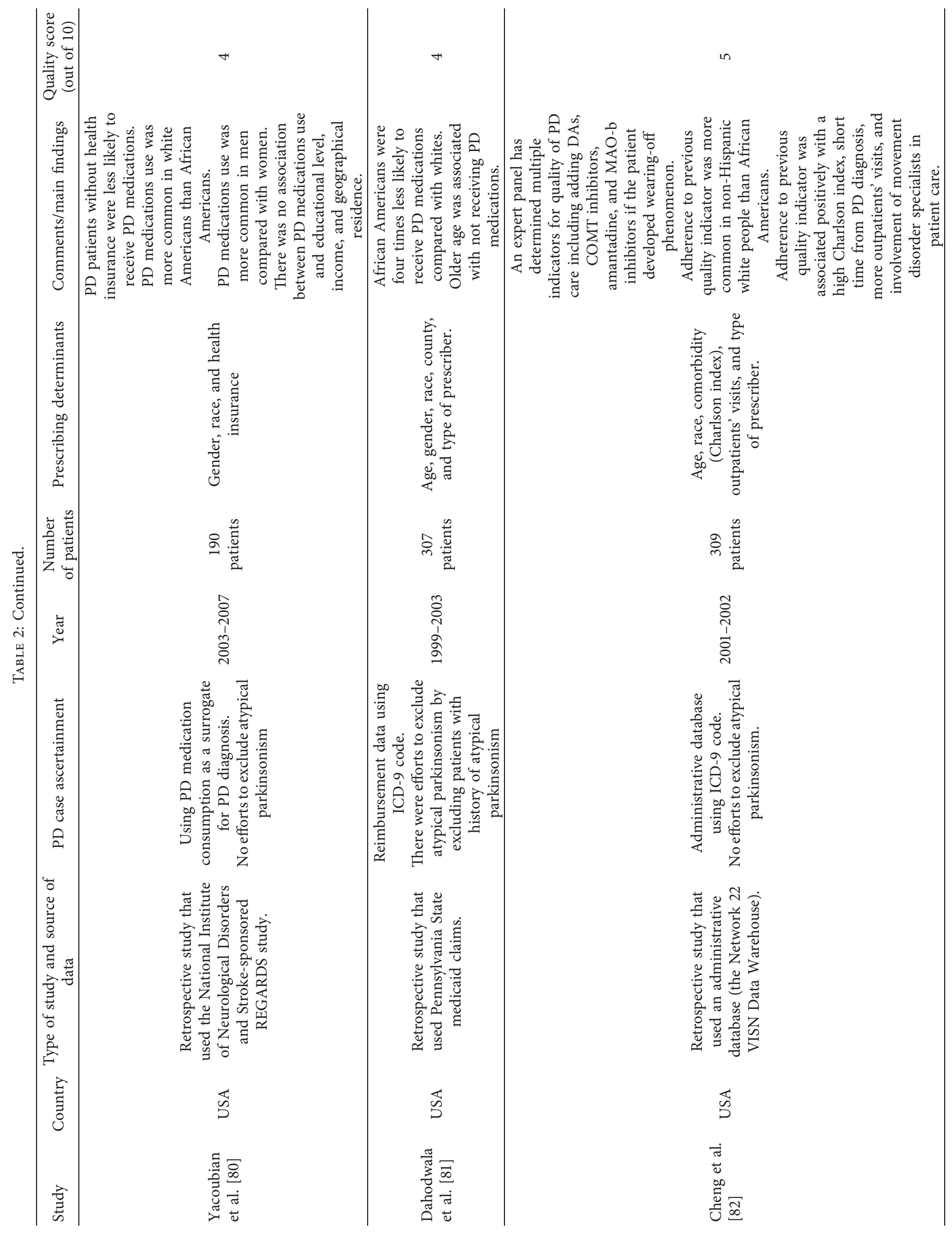




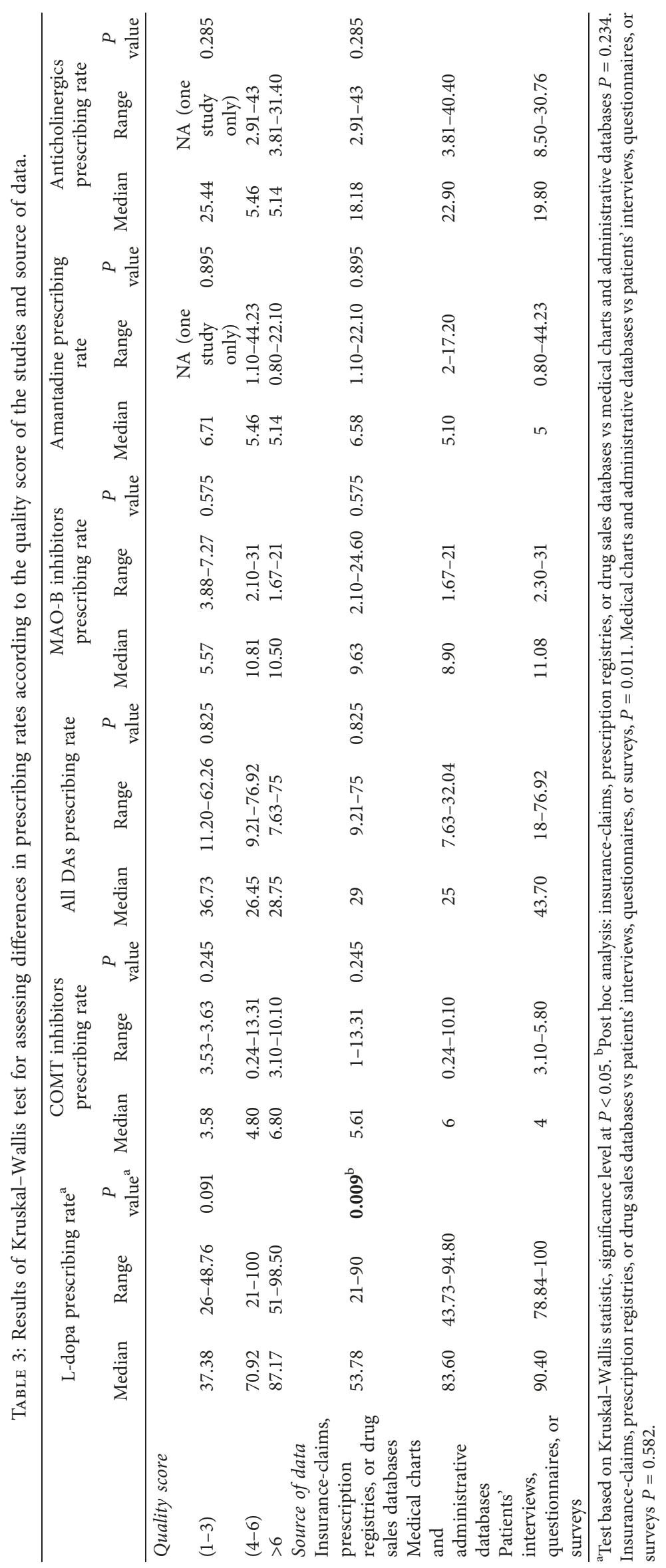


TABLE 4: Summary of prescribing trends of PD medications and factors associated with their use.

\begin{tabular}{|c|c|c|c|c|c|c|}
\hline & L-dopa & $\begin{array}{c}\text { Dopamine } \\
\text { agonists (DAs) }\end{array}$ & COMT inhibitors & MAO-B inhibitors & Amantadine & Anticholinergics \\
\hline $\begin{array}{l}\text { General } \\
\text { prescribing } \\
\text { pattern }\end{array}$ & $\begin{array}{l}\text { L-dopa was the } \\
\text { most commonly } \\
\text { prescribed } \\
\text { medication in } \\
\text { most studies } \\
\text { regardless of the } \\
\text { year or the design } \\
\text { of the study } \\
\text { ranged from } \\
37.42 \% \text { (in Spain) } \\
\text { to } 100 \% \text { (in India). } \\
\text { Only one } \\
\text { Norwegian study } \\
\text { examined the } \\
\text { prescribing rate of } \\
\text { L-dopa intestinal } \\
\text { gel (LCIG). }\end{array}$ & $\begin{array}{l}\text { DAs (non-ergots } \\
\text { mainly) were the } \\
\text { second most } \\
\text { common PD } \\
\text { medication } \\
\text { prescribed in } 16 \\
\text { studies with the } \\
\text { prescription rate } \\
\text { ranging from } \\
7.63 \% \text { to } 85 \% \text {. } \\
\text { Studies carried out } \\
\text { prior to } 2000 \\
\text { showed higher } \\
\text { prescription rates } \\
\text { of ergot DAs than } \\
\text { those carried out } \\
\text { after } 2000 . \\
\text { There were no } \\
\text { data from most } \\
\text { studies regarding } \\
\text { apomorphine } \\
\text { usage. }\end{array}$ & $\begin{array}{l}\text { Large variation in } \\
\text { the prescribing } \\
\text { rates of COMT } \\
\text { inhibitor } \\
\text { monotherapy } \\
\text { ranged from } \\
1.01 \% \text { in USA to } \\
29 \% \text { in USA as } \\
\text { well. }\end{array}$ & $\begin{array}{l}\text { There were } \\
\text { variations in the } \\
\text { prescription rates } \\
\text { of MAO-B } \\
\text { inhibitors ranging } \\
\text { from } 2.12 \% \text { in } \\
\text { South Africa to } \\
42 \% \text { in Japan. }\end{array}$ & $\begin{array}{l}\text { There was wide } \\
\text { variation, ranging } \\
\text { from } 0.2 \% \text { in Italy } \\
\text { to } 44.23 \% \text { in } \\
\text { Japan. }\end{array}$ & $\begin{array}{l}\text { A significant } \\
\text { variation was } \\
\text { noticed in the } \\
\text { cross-sectional } \\
\text { studies that } \\
\text { examined } \\
\text { anticholinergic } \\
\text { use in PD. } \\
\text { In some Asian } \\
\text { countries (India, } \\
\text { Japan, and } \\
\text { Singapore), } \\
\text { anticholinergics } \\
\text { prove more } \\
\text { popular with a } \\
\text { high prescription } \\
\text { rate ranging from } \\
22.9 \% \text { in } \\
\text { Singapore to } \\
40.4 \% \text { in India. }\end{array}$ \\
\hline $\begin{array}{l}\text { Trend of } \\
\text { prescribing } \\
\text { across years }\end{array}$ & $\begin{array}{l}\text { There was an } \\
\text { increase in L-dopa } \\
\text { prescribing across } \\
\text { time in Sweden, } \\
\text { Spain, and } \\
\text { Europe. } \\
\text { A decrease in L- } \\
\text { dopa prescribing } \\
\text { across time was } \\
\text { observed in } \\
\text { Southern Italy, } \\
\text { Japan, USA, } \\
\text { Finland, and } \\
\text { Taiwan. }\end{array}$ & $\begin{array}{l}\text { A general decrease } \\
\text { in prescription } \\
\text { rates of ergot DAs } \\
\text { and an increase in } \\
\text { the trend of non- } \\
\text { ergot DAs } \\
\text { prescription rates } \\
\text { were observed in } \\
\text { several countries } \\
\text { especially after } \\
2000 .\end{array}$ & $\begin{array}{c}\text { Prescribing } \\
\text { increase was } \\
\text { observed in the } \\
\text { USA, New } \\
\text { Zealand, and } \\
\text { Japan. On the } \\
\text { contrary, studies } \\
\text { based in Australia, } \\
\text { Europe, and Spain } \\
\text { showed a slight } \\
\text { decrease in } \\
\text { prescribing. }\end{array}$ & $\begin{array}{c}\text { Selegiline } \\
\text { prescribing was } \\
\text { either maintained } \\
\text { or decreased } \\
\text { across years. } \\
\text { Only two studies } \\
\text { revealed a slight } \\
\text { increase of MAO- } \\
\text { B inhibitors } \\
\text { (Rasagline } \\
\text { mainly) } \\
\text { prescribed over } \\
\text { time in Finland } \\
\text { and Europe. }\end{array}$ & $\begin{array}{l}\text { Across years, a } \\
\text { relatively steady } \\
\text { prescribing rate of } \\
\text { amantadine was } \\
\text { observed in the } \\
\text { USA, Australia, } \\
\text { and Europe. } \\
\text { A general decrease } \\
\text { in prescription } \\
\text { rates was seen in } \\
\text { Japan, and an } \\
\text { increase in the } \\
\text { trend of } \\
\text { prescription rates } \\
\text { was observed in } \\
\text { New Zealand. }\end{array}$ & $\begin{array}{l}\text { Most studies have } \\
\text { shown a decrease } \\
\text { in prescription } \\
\text { rates of } \\
\text { anticholinergics } \\
\text { across years }\end{array}$ \\
\hline \multicolumn{7}{|l|}{ Patient factors } \\
\hline Age & $\begin{array}{l}\text { Elderly patients } \\
\text { (age } \geq 65 \text { years or } \\
\text { age } \geq 70 \text { years) } \\
\text { were more likely } \\
\text { to be prescribed L- } \\
\text { dopa than } \\
\text { younger patients. }\end{array}$ & $\begin{array}{l}\text { DAs use was less } \\
\text { common in } \\
\text { elderly patients } \\
\text { with some } \\
\text { exceptions as in } \\
\text { some USA } \\
\text { hospitals. }\end{array}$ & $\mathrm{N} / \mathrm{A}$ & $\begin{array}{l}\text { Comparative } \\
\text { Italian study that } \\
\text { examined MAO-B } \\
\text { users found that } \\
\text { rasagiline } \\
\text { utilisation was } \\
\text { more common in } \\
\text { younger patients } \\
\text { than selegiline. }\end{array}$ & $\mathrm{N} / \mathrm{A}$ & $\begin{array}{l}\text { In two studies, } \\
\text { elderly patients } \\
\text { were less likely to } \\
\text { be prescribed or } \\
\text { initiated on } \\
\text { anticholinergics. }\end{array}$ \\
\hline Gender & $\begin{array}{l}\text { Multiple studies } \\
\text { found no } \\
\text { difference } \\
\text { between men and } \\
\text { women in the } \\
\text { likelihood of L- } \\
\text { dopa prescribing. }\end{array}$ & $\begin{array}{l}\text { Multiple studies } \\
\text { found no } \\
\text { difference } \\
\text { between men and } \\
\text { women in the } \\
\text { likelihood of DAs } \\
\text { prescribing. }\end{array}$ & N/A & $\begin{array}{l}\text { One Italian study } \\
\text { found that } \\
\text { rasagiline was } \\
\text { more commonly } \\
\text { prescribed to men } \\
\text { than selegiline. }\end{array}$ & $\mathrm{N} / \mathrm{A}$ & N/A \\
\hline
\end{tabular}


TABle 4: Continued.

\begin{tabular}{|c|c|c|c|c|c|c|}
\hline & L-dopa & $\begin{array}{c}\text { Dopamine } \\
\text { agonists (DAs) }\end{array}$ & COMT inhibitors & MAO-B inhibitors & Amantadine & Anticholinergics \\
\hline Race & N/A & $\begin{array}{l}\text { In USA, DAs } \\
\text { prescribing was } \\
\text { more common in } \\
\text { non-Hispanic } \\
\text { white people when } \\
\text { compared to } \\
\text { African } \\
\text { Americans, } \\
\text { although this } \\
\text { finding was not } \\
\text { statistically } \\
\text { significant. }\end{array}$ & $\begin{array}{l}\text { In USA, COMT } \\
\text { inhibitors } \\
\text { prescribing was } \\
\text { more common in } \\
\text { non-Hispanic } \\
\text { white people when } \\
\text { compared to } \\
\text { African } \\
\text { Americans, } \\
\text { although this } \\
\text { finding was not } \\
\text { statistically } \\
\text { significant. }\end{array}$ & $\begin{array}{l}\text { In USA, MAO-B } \\
\text { inhibitors } \\
\text { prescribing was } \\
\text { more common in } \\
\text { non-Hispanic } \\
\text { white people when } \\
\text { compared to } \\
\text { African } \\
\text { Americans, } \\
\text { although this } \\
\text { finding was not } \\
\text { statistically } \\
\text { significant. }\end{array}$ & $\begin{array}{c}\text { In USA, } \\
\text { amantadine } \\
\text { prescribing was } \\
\text { more common in } \\
\text { non-Hispanic } \\
\text { white people when } \\
\text { compared to } \\
\text { African } \\
\text { Americans, } \\
\text { although this } \\
\text { finding was not } \\
\text { statistically } \\
\text { significant. }\end{array}$ & N/A \\
\hline $\begin{array}{l}\text { Duration of the } \\
\text { disease }\end{array}$ & $\begin{array}{c}\text { Number of years } \\
\text { since PD } \\
\text { diagnosis was } \\
\text { lower in L-dopa } \\
\text { monotherapy } \\
\text { users than DAs } \\
\text { monotherapy } \\
\text { users. }\end{array}$ & $\begin{array}{c}\text { Number of years } \\
\text { since PD } \\
\text { diagnosis was } \\
\text { lower in L-dopa } \\
\text { monotherapy } \\
\text { users than DAs } \\
\text { monotherapy } \\
\text { users. }\end{array}$ & N/A & N/A & N/A & N/A \\
\hline Comorbidities & N/A & $\begin{array}{l}\text { DAs prescribing } \\
\text { was more } \\
\text { common in } \\
\text { patients with a } \\
\text { high comorbidity } \\
\text { score. }\end{array}$ & $\begin{array}{l}\text { COMT inhibitor } \\
\text { prescribing was } \\
\text { more common in } \\
\text { patients with a } \\
\text { high comorbidity } \\
\text { score. }\end{array}$ & $\begin{array}{l}\text { MAO-B inhibitor } \\
\text { prescribing was } \\
\text { more common in } \\
\text { patients with a } \\
\text { high comorbidity } \\
\text { score. }\end{array}$ & $\begin{array}{l}\text { Amantadine } \\
\text { prescribing was } \\
\text { more common in } \\
\text { patients with a } \\
\text { high comorbidity } \\
\text { score. }\end{array}$ & $\begin{array}{l}\text { Patients with PD } \\
\text { and dementia } \\
\text { were prescribed } \\
\text { anticholinergics as } \\
\text { initial therapy } \\
\text { more commonly } \\
\text { than non- } \\
\text { dementia patients. }\end{array}$ \\
\hline $\begin{array}{l}\text { Socioeconomic } \\
\text { status and care } \\
\text { settings }\end{array}$ & $\begin{array}{l}\text { L-dopa equivalent } \\
\text { daily dose (LEDD) } \\
\text { prescribed to care } \\
\text { home residents } \\
\text { was lower than } \\
\text { that prescribed to } \\
\text { the patients in the } \\
\text { community. }\end{array}$ & $\begin{array}{l}\text { Patients with a } \\
\text { higher education } \\
\text { level were } \\
\text { prescribed DAs } \\
\text { more often than } \\
\text { patients with a } \\
\text { lower education } \\
\text { level. } \\
\text { Patients residing } \\
\text { in institutions } \\
\text { were less } \\
\text { commonly } \\
\text { prescribed DAs } \\
\text { than residents } \\
\text { within the } \\
\text { community. }\end{array}$ & $\begin{array}{l}\text { COMT inhibitor } \\
\text { prescribing was } \\
\text { higher in patients } \\
\text { living in their } \\
\text { homes compared } \\
\text { to care homes } \\
\text { patients. }\end{array}$ & $\begin{array}{l}\text { MAO-B inhibitor } \\
\text { prescribing was } \\
\text { higher in patients } \\
\text { living in their } \\
\text { homes compared } \\
\text { to care homes } \\
\text { patients. }\end{array}$ & N/A & N/A \\
\hline $\begin{array}{l}\text { Geographical } \\
\text { location }\end{array}$ & $\begin{array}{l}\text { One Norwegian } \\
\text { study found that } \\
\text { patients living in } \\
\text { Rogaland county } \\
\text { were significantly } \\
\text { prescribed more } \\
\text { L-dopa intestinal } \\
\text { gel than other } \\
\text { counties in } \\
\text { Norway. }\end{array}$ & N/A & N/A & N/A & N/A & N/A \\
\hline
\end{tabular}


TABLE 4: Continued.

\begin{tabular}{|c|c|c|c|c|c|c|}
\hline & L-dopa & $\begin{array}{c}\text { Dopamine } \\
\text { agonists (DAs) }\end{array}$ & COMT inhibitors & MAO-B inhibitors & Amantadine & Anticholinergics \\
\hline \multicolumn{7}{|l|}{$\begin{array}{l}\text { Prescribers' } \\
\text { factors }\end{array}$} \\
\hline $\begin{array}{l}\text { Type of } \\
\text { prescriber }\end{array}$ & $\begin{array}{l}\text { In USA, half of the } \\
\text { family physicians } \\
\text { and almost one } \\
\text { third of the } \\
\text { neurologists } \\
\text { prescribe L-dopa } \\
\text { as a starting } \\
\text { therapy for PD } \\
\text { patients } \\
\text { immediately after } \\
\text { diagnosis. } \\
\text { In Spain, no } \\
\text { significant } \\
\text { difference was } \\
\text { found in the } \\
\text { percentages of } \\
\text { prescribers of L- } \\
\text { dopa among } \\
\text { family physicians, } \\
\text { geriatricians, } \\
\text { neurologists, and } \\
\text { movement } \\
\text { disorder } \\
\text { specialists. }\end{array}$ & $\begin{array}{c}\text { In Spain, } \\
\text { movement } \\
\text { disorders } \\
\text { specialists tended } \\
\text { to prescribe DAs } \\
\text { more than general } \\
\text { practitioners }\end{array}$ & N/A & N/A & $\begin{array}{l}\text { In Spain, } \\
\text { movement } \\
\text { disorders } \\
\text { specialists tended } \\
\text { to prescribe } \\
\text { amantadine } \\
\text { exclusively. }\end{array}$ & $\begin{array}{l}\text { In the USA, } \\
\text { mental health } \\
\text { providers were } \\
\text { more likely to } \\
\text { prescribe } \\
\text { anticholinergics as } \\
\text { an initial therapy } \\
\text { than other } \\
\text { prescribers. } \\
\text { In Spain, the } \\
\text { percentage of } \\
\text { patients treated } \\
\text { with } \\
\text { anticholinergics } \\
\text { was higher if they } \\
\text { were treated by } \\
\text { family physicians }\end{array}$ \\
\hline
\end{tabular}

categories of PD medication prescription rates. One exception to these rules was a study carried out in Taiwan that used the number of prescriptions as a unit of analysis [46]. The total prescription rates of all PD medications exceed $100 \%$ due to the fact that some prescriptions include more than one medication. The prescription rates could not be calculated for any of the PD medications in four studies [44, $50,56,63]$.

3.2. Quality of the Studies. The quality assessment of the selected studies using the Joanna Briggs Institute Critical Appraisal Tool is illustrated in Part 6 of Supplementary Materials. Out of the prescribing pattern and determinants studies $(n=43)$, two studies were given a quality score of 9 out of $10(9 /$ 10) $[45,49]$, four studies were given $8 / 10[46,54,63,70]$, seven studies were given $7 / 10[51,56,68,73]$, six studies were given $6 /$ $10[48,52,66,69,71,75]$, eleven studies were given $5 / 10$ $[50,55,57,60,61,64,65,72]$, ten studies were given $4 / 10$ $[42-44,47,62,67,74]$, three studies were given $3 / 10$ $[41,53,58]$, and finally, one study was given $2 / 10$ [59].

3.3. Prescribing Patterns. PD medication prescription rates in all the countries included in this review are presented in Part 7 of Supplementary Materials. Additionally, Table 4 shows a grand summary of PD medications' prescribing pattern.

3.3.1. L-Dopa. All of the studies except five $[44,48,50,56,63]$ calculated the prescription rate of L-dopa. Out of the studies that calculated L-dopa prescription rates, four calculated the prescription rates of L-dopa-carbidopa and L-dopa-carbidopa-entacapone combinations separately [43, 58, 62, 84]; seven studies calculated the prescription rates of both L-dopacarbidopa and L-dopa-carbidopa-entacapone combinations altogether without distinction $[45,47,51,57,60,64,65]$, and the rest of the studies calculated only L-dopa-carbidopa prescription rates $[42,46,53-55,59,61,66-75,83]$. None of the studies that used hospital data mentioned if LCIG prescribing rate was calculated except for one Norwegian study [41]. The Norwegian study found the average number of patients using L-dopa gel to be 2.6 per 100,000 population which was less than the number of patients using deep brain stimulation (DBS) (2.9 per 100,000 population) [41].

Except for a few studies [53, 61, 62, 83], L-dopa was the most commonly prescribed medication in all the studies regardless of the year or the design of the study, accounting for between $37.42 \%$ (in Spain) and 100\% (in India) of all PD medications $[55,67]$.

L-dopa prescription rates were the highest (ranging from $46.50 \%$ to $100 \%$ ) compared to other PD medications in several cross-sectional studies in Italy [73, 75], Japan [74], Spain [71], Singapore [70], USA [45, 64, 69], Sweden and Norway [84], South Africa [57], and India [42, 43, 55]. The lowest L-dopa prescription rates were $21 \%$ in 2005 and 2008, found in a Japanese study that used the National Japanese Database to examine the effect of pergolide withdrawal from the USA market on PD medication prescribing patterns in Japan by applying a time interrupted series model [61]. L-dopa did not account for the majority of prescription rates 
in New Zealand (24.86\% in 1995) [53] or Australia (36.50\% in 1995) [62]. However, both studies reported that L-dopa prescription rates had increased and accounted for the majority of prescribing in 2011 in New Zealand (48.76\%) and in 2009 in Australia (52.30\%).

Studies carried out in other countries found an increase in the prescription rates of L-dopa in different years. Figure 3(a) shows that L-dopa prescriptions increased in Sweden, Spain, and Europe in general $[65,67,72]$. Inversely, Figure 3(a) shows a decrease in the prescription rates of L-dopa over the years in Southern Italy, Japan, USA, Finland, and Taiwan $[46,47,51,54,66]$.

3.3.2. Dopamine Agonists. All bar five studies calculated the prescription rates of DAs (ergot, non-ergot, or both) [44, 50, $56,63,75]$. Studies that calculated prescribing patterns of DAs can be classified under studies that calculated both ergot and non-ergot DAs prescription rates $[43,51,53,54$, $58,61,62,66,67,71,73]$; DAs prescription rates in general without specifying what type of DAs $[42,45-47,59,60,64$, $65,68,69,72,83,84]$; ergot DAs only [70, 74]; or, non-ergot DAs only [48, 55, 57]. Only four studies examined apomorphine prescribing but without specifying its pharmaceutical formulation forms (subcutaneous injection vs subcutaneous infusion) $[53,62,67,73]$.

In general, DAs were the second most common PD medication prescribed after L-dopa in 16 studies with the prescription rate ranging from $7.63 \%$ to $85 \%$ [45-48, 51, 54, $57,59,64,66,68-71,73,74,84]$. Only one study that examined the pattern of prescribing in nursing homes in five states in the USA found that DAs were the most commonly prescribed PD medication to the members of the study sample, surpassing even L-dopa (75\% out of 10,738 PD medications users) [83]. In small number of studies, anticholinergics bumped DAs into third place, ranging from $10.90 \%$ to $29 \%$ either throughout the study, as in India [42, 43, 55], New Zealand [53], and Japan [61], or at least at one point during the study as in Spain in 1992 [67] and Australia in 2009 [62]. In only 1 retrospective study in Sweden, DAs prescription rates were third after L-dopa and MAO-B inhibitors [72] although DA agonist prescribing continued to grow. Aligned with the Swedish study, a gradual increase in the trend of DAs prescription rates over the years is evident in many countries $[46,47,51,53,61,62,66,67]$ (see Figure 4(c)). Studies from Australia, New Zealand, Spain, and Italy revealed a slight increase in the use of apomorphine after it became available in these countries $[53,62,67,73]$. There were no data from other countries regarding apomorphine usage.

(1) Ergot-Based DAs. Out of all prescribing pattern studies, thirteen studies calculated the exact prescription rates of ergot DAs $[43,51,53,54,58,61,62,66,67,70,71,73,74]$. There was a wide range in the prescription rates of ergot DAs which ranged from $0.50 \%$ to $76.92 \%$. For studies that calculated the rate of prescribing at only one point of time, there was often an association between the year of the study and the prescription rates. For example, studies carried out prior to 2000 showed higher prescription rates of ergot DAs than these carried out after 2000. Studies that examined the changes in prescription rates across a number of years found a general decrease in prescription rates of ergot DAs [51, 53, $54,58,61,67$ ] ranging from a $3 \%$ decrease in prescription rates in Japan between 2005 and 2008 [61] to 30.69\% sales costs decrease in England between 1999 and 2010 [58]. The exception was two studies in Australia and Southern Italy show a slight increase in ergot DAs prescription rates [62, 66]. The Australian study revealed an increase in ergot DAs prescription rates from $4.10 \%$ in 1995 to $4.80 \%$ in 2009 [62] and the Italian study found about $5 \%$ increase in the prevalence of ergot DAs use per 100,000 inhabitants between 2003 and 2005 [66] (Figure 4(a)).

(2) Non-Ergot DAs. Fourteen studies measured the exact prescription rate of non-ergot DAs $[43,48,51,53-55,57,58$, $61,62,66,67,71,73]$. Of these, nine calculated the prescription rates at only one time and found that the prescription rates of non-ergot DAs ranged from 5.9\% in Australia [62] to $39.80 \%$ in South Africa [57]. An increase in the trend of non-ergot DAs prescription rates was observed in several countries [51, $54,58,61,66]$. This increase was dramatic in some studies, for instance in England there was a $49.2 \%$ increase in non-ergot DAs sales rates between 1999 and 2010 [58]. Typically though, a more modest increase in prescription rates of non-ergot DAs was observed; for instance, in the USA (13\% increase between 2001 and 2011) [51], Japan (28.2\% increase between 2005 and 2010 or 5.2\% increase between 2005 and 2008) [54, 61], and Southern Italy (1.88\% increase between 2003 and 2005) [66]. Although there was a general increase in non-ergot DAs prescription rates in an American study carried out in an inpatient setting across a number of years, the prescription rate of non-ergot DAs decreased from $33.4 \%$ in 2008 to $27.9 \%$ in 2011 following addition of the gambling precaution (which is one of the impulse control disorders (ICDs) forms associated with DAs) to the pramipexole profile in 2008 [51] (Figure 4(b)). Apart from the previous American study (51), only two studies clearly stated the impact of ICDs on non-ergot DAs prescribing and both have shown an increase in non-ergot DAs prescribing in Taiwan (46) and England (58) which revealed no impact of ICDs reports on non-ergots DA prescribing trends.

3.3.3. COMT Inhibitors. The pattern of prescribing of COMT inhibitors was examined in several studies $[43,45$, $47,51,53-55,57-62,64,65,67,69-73]$. While only two studies calculated the prescribing rate of the entacapone combination (L-dopa-carbidopa-entacapone combination) with a clear distinction between rates of L-dopa- carbidopa and L-dopa-carbidopa-entacapone combinations [43, 84], several studies have considered L-dopa-carbidopa and L-dopa-carbidopa-entacapone combinations as being one group without clear distinctions $[45,47,51,57,58,60,64$, 65]. For COMT inhibitor monotherapy, some studies calculated the prescribing rates of tolcapone monotherapy [73], entacapone monotherapy $[43,54,55,58,61,62,67,69,71]$, or both $[39,51,53,59,64,65,70,72]$. COMT inhibitor 


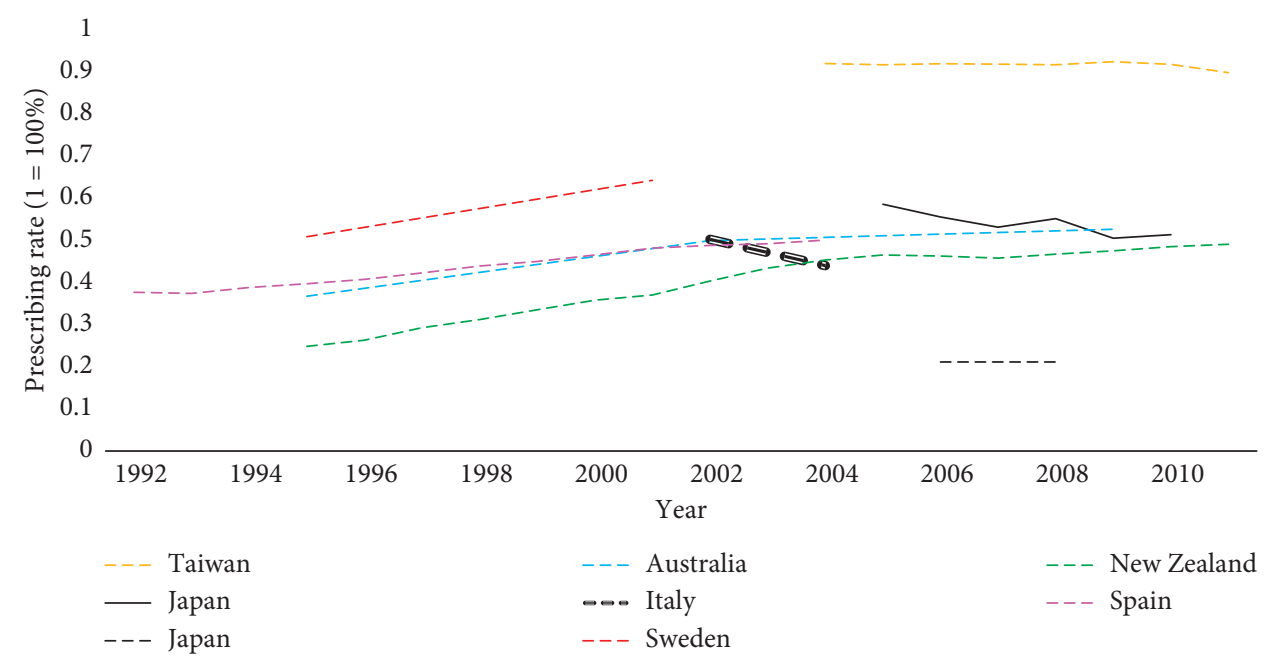

(a)

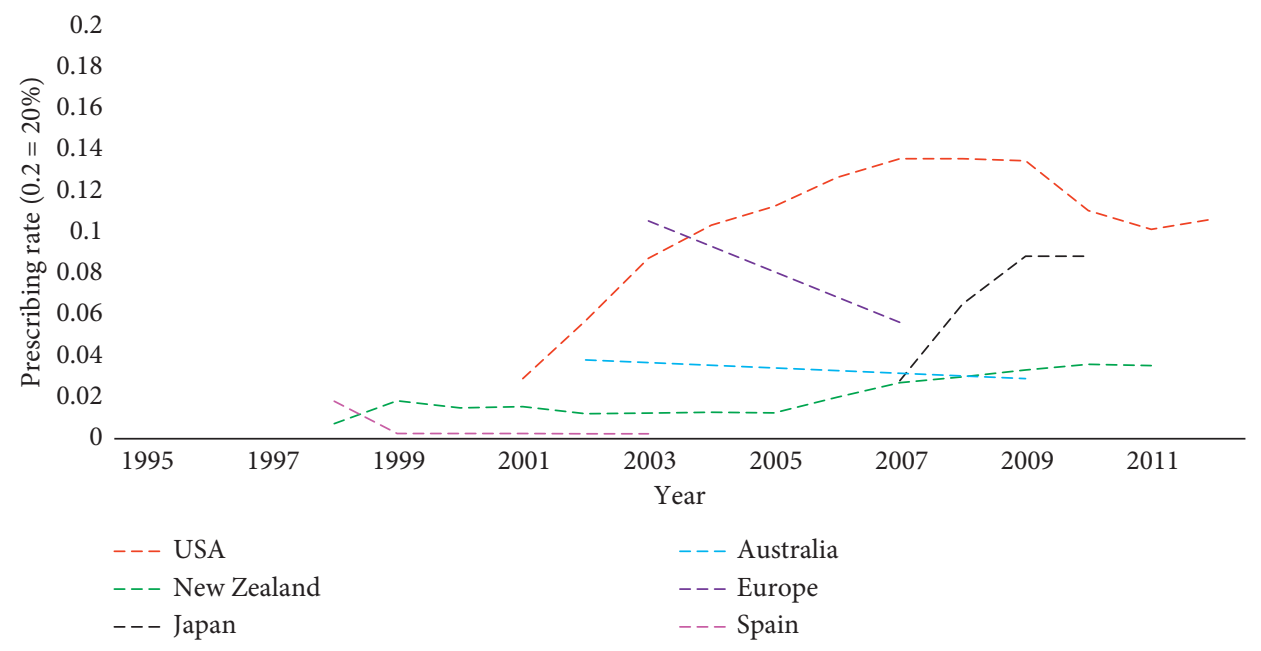

(b)

FIgure 3: Prescribing trends of PD medications. (a) L-dopa (without entacapone combinations). (b) COMT inhibitors.

monotherapy prescribing in the cross-sectional studies ranged from $1.01 \%$ in the USA in $1999-2000$ [69] to $29 \%$ in the USA in 2003 [59]. An increase was observed in the USA (2.9\% in 2001 to $10.6 \%$ in 2012$)$ [51], New Zealand $(0.73 \%$ in 1998 to $3.53 \%$ in 2011$)$ [53], and Japan (2.80\% in 2007 to $8.80 \%$ in 2010) [54]. On the contrary, studies based in Australia, Europe, and Spain showed a slight decrease in COMT inhibitors prescribing [62, 65, 67] (Figure 3(b)). Although a previous study in Europe found a similar decrease in COMT inhibitor prescribing rates, it revealed a significant increase in L-dopa-carbidopa and L-dopa-carbidopa-entacapone combination sales by $68 \%$ between 2003 and 2007. As it is accompanied by a decrease in entacapone monotherapy prescribing over the same period, this likely reflects increasing sales of L-dopa-carbidopa-entacapone combinations [65].

3.3.4. MAO-B Inhibitors. MAO-B inhibitor prescribing patterns were explored in the majority of the identified studies $[43,45,47,48,51,53-55,57-62,64,65,67-73,75$, 84]. Out of the two MAO-B inhibitors available, the selegiline prescription rate was measured in 17 studies $[53,54$, $57,60-62,64,67-73,75,83,84]$, both selegiline and rasagiline prescription rates were measured in 6 studies $[47,48$, $51,55,58,65]$, and the rest of the studies measured MAO-B inhibitors as a group without specifying the name of the drug $[45,59]$. There were variations in the prescription rates of MAO-B inhibitors in the cross-sectional studies, which ranged from $2.12 \%$ in South Africa [57] to $42 \%$ in Japan [59]. Other studies that examined changes in the trend of prescription rates over the years revealed varying trends. Selegiline prescribing was either maintained or decreased [53, 54, 61, 62, 67, 72] (Figure 5(a)). Decreases were particularly notable in Sweden between 1995 and 2001 (28\% decrease in sales) [72] and New Zealand (18.76\% in 1995 to $3.88 \%$ in 2011) [53]. A relative steady prescribing rate of selegiline was seen in Japan [54, 61], Australia [62], and Spain [67] (Figure 5(a)). Some studies calculated selegiline rates in the beginning of the study and after calculating both 


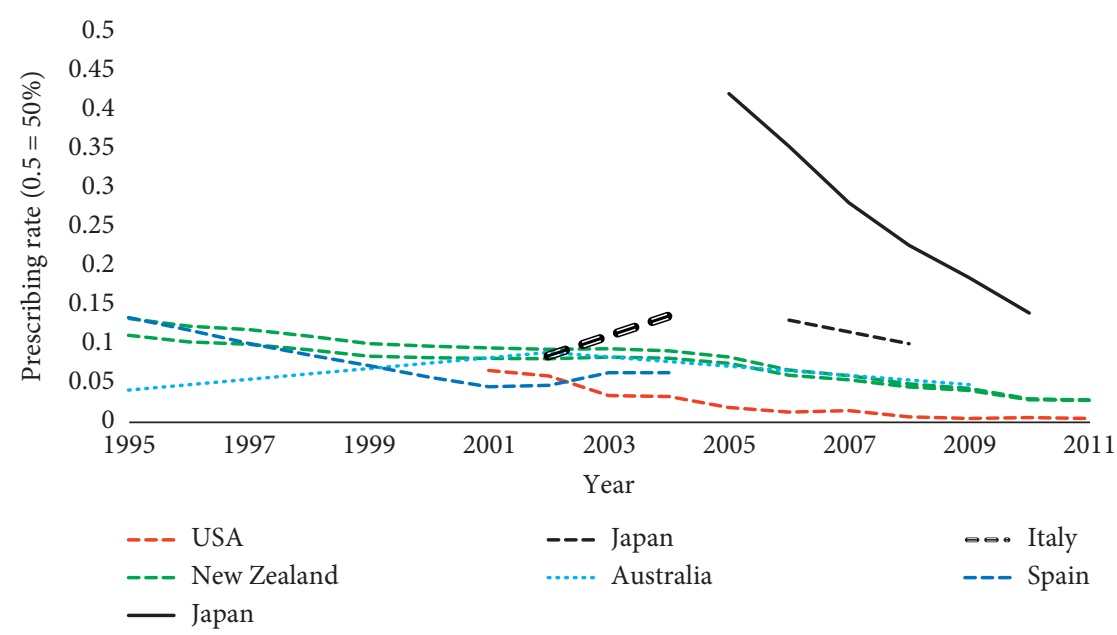

(a)

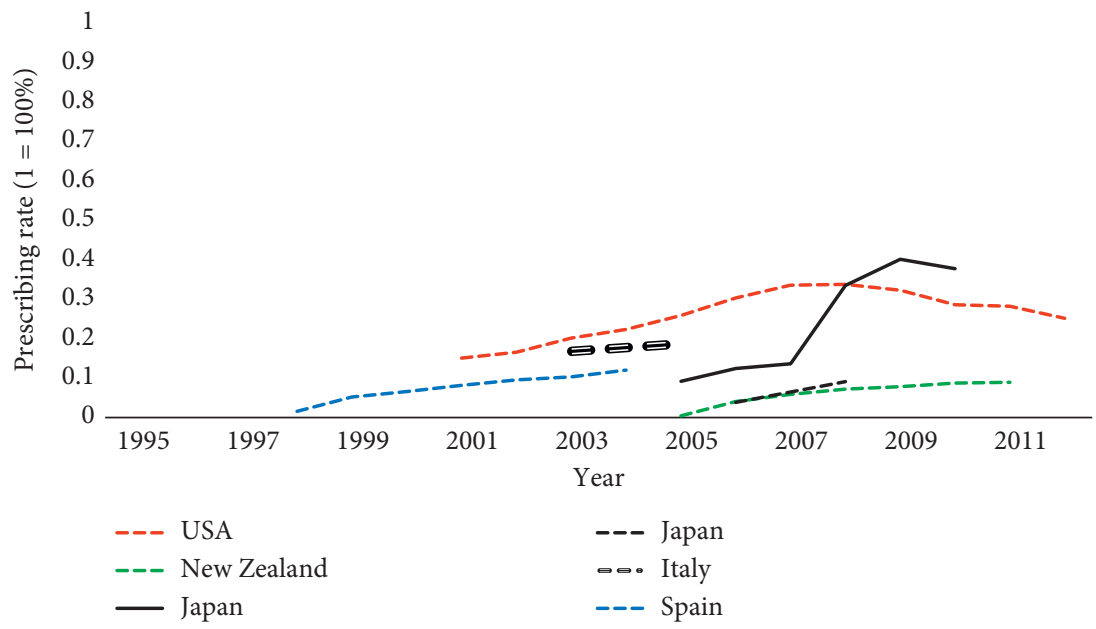

(b)

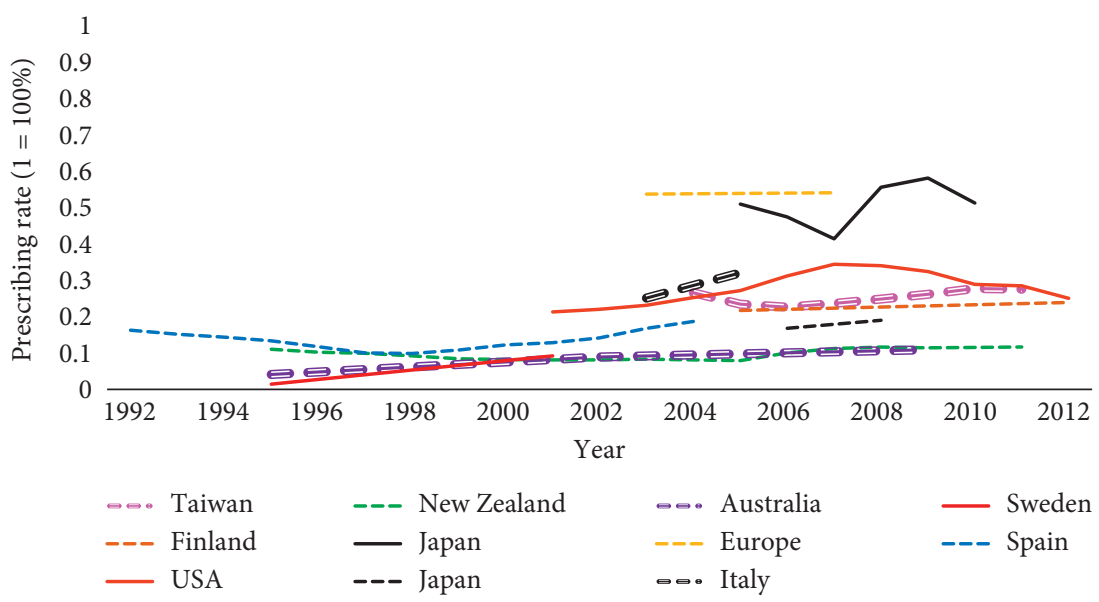

(c)

Figure 4: Prescribing trends of PD medications. (a) Ergot dopamine agonists. (b) Non-ergot dopamine agonists. (c) All dopamine agonists.

selegiline and rasagiline rates (as a group) when rasagiline became commercially available $[47,51,58,65]$. Only two studies revealed a slight increase of MAO-B inhibitors prescribing over time (9.90\% in 2005 to $14.10 \%$ in 2012 in Finland and $3.89 \%$ in 2003 to $5.80 \%$ in Europe) [47, 65] (Figure 5(a)).
3.3.5. Amantadine. A total of 20 studies measured prescribing rates of amantadine $[42,43,45,48,51,53-55,57$, 60-62, 64, 65, 68-71, 73, 74]. Among cross-sectional studies, there was wide variation, ranging from $0.2 \%$ in Italy [73] to $44.23 \%$ in Japan [74]. In trend studies, a steady prescribing rate of amantadine was observed in the USA (6.20\% in 2001 
and $6.80 \%$ in 2012) [51], Australia (2.90\% in 1995 and $3.50 \%$ in 2009) [62], and Europe (1.86\% in 2003 and $1.10 \%$ in 2007) [65]. In Japan, 2 studies showed two different trends, i.e., Nakaoka et al. found a decrease in amantadine prescribing from $30 \%$ in 2005 to $22.10 \%$ in 2010 [54], while Ooba et al. found no major changes between 2006 and 2008 (11\% and $10 \%$, respectively) [61]. A noticeable increase in amantadine use was seen in New Zealand (1.26\% in 1995 and $6.71 \%$ in 2011) [53] (Figure 5(b)).

3.3.6. Anticholinergics. A significant variation was noticed in the cross-sectional studies that examined anticholinergic use in PD patients. Two recent studies in the USA examined anticholinergics prescribing in inpatient and community settings and revealed low prescribing rates of anticholinergics (5\% and 6.6\%) $[45,64]$. This suggests a decreasing trend overall when compared to an earlier study $(18.18 \%$ between 1992 and 1996) [83]. In some Asian countries (India, Japan, and Singapore), anticholinergics prove more popular with a relatively high prescription rate ranging from $22.9 \%$ in Singapore to $40.4 \%$ in India $[42,70]$. In trend studies, most studies have shown a decrease in prescription rates of anticholinergics across years. This decrease was slight in some countries such as in USA (6.70\% in 2001 to $6.10 \%$ in 2012) [51]. A more observable decrease was seen in other countries such as in New Zealand (44.30\% in 1995 to $25.44 \%$ in 2011) [53] (Figure 5(c)).

3.4. Prescribing and Drug Utilisation Determinants. Once the determinants of the prescription and utilisation of PD medications are extracted, they could be classified according to patient factors (with several subcategories) and prescriber factors (with only one subcategory). Table 4 shows a summary of prescribing determinants of PD medications.

\subsubsection{Patient Factors}

(1) Age. Several studies have shown that elderly patients (age $\geq 65$ years or age $\geq 70$ years) were more likely to be prescribed L-dopa than younger patients $[45,47,51,54,57$, $60,63,69]$. The L-dopa dose was inversely associated with age in an examination of 33,534 L-dopa users in Sweden [79]. Moreover, in two studies, elderly patients were less likely to be prescribed [54] or initiated on anticholinergics [68]. In contrast, with the use of L-dopa, and consistent with guidance of preferred L-dopa use in the elderly, the use of DAs was less common in elderly patients $[45,51]$. However, there were studies that were discrepant; Crispo et al. found that elderly people in inpatient hospital settings in the USA were regularly prescribed DAs, regardless of national guidelines [51]. Studies have looked at the overall likelihood of receiving $\mathrm{PD}$ medications based on age two of which suggested that older patients $(>85)$ were less likely to be medicated $[64,83]$. Conversely, Dahodwala et al. similarly in the USA determined that older patients were more likely to receive $\mathrm{PD}$ medications than younger patients $(\mathrm{OR}=1.67$, 95\% CI, 1.17-3.27) [81].
On the contrary, a study of younger patients ( $\leq 60$ years, or $\leq 65$ years) revealed a different pattern of prescribing than that pertaining to older patients. Younger patients were more likely to be prescribed DAs in multiple studies and tended to receive more than one medication to treat PD [45, $51,79]$. There is significant country to country variation in the management of younger patients with PD with one US study finding that the majority of younger patients in the study were prescribed L-dopa, while only $20 \%$ of younger patients (or $\leq 65$ years) were on DAs [68]. MAO-B inhibitors and anticholinergics were more likely to be prescribed as an initial therapy to younger patients than L-dopa in a Taiwanese study [56]. With regard to MAO-B inhibitors, a comparative Italian study that examined 1607 MAO-B users found that rasagiline utilisation was more common in younger patients than selegiline [50]. In trend studies, a Finnish study found that the use of MAO-B inhibitors was increased during the duration of the study (from 2005 to 2011) in younger patients [47].

(2) Gender. Multiple studies found no difference between men and women in terms of L-dopa and DAs prescription rates $[51,52,64,66,69]$. However, where differences were observed, they were generally indicated men receiving higher doses or to be more likely to receive multiple medications [45, 79, 80, 83]. The effect of gender on the prescribing of other types of PD medications (other than L-dopa and DAs) was not evaluated in all the studies in this review. However, in one study, it was found that rasagiline was more commonly prescribed to men than selegiline, i.e., $45.2 \%$ of selegiline users $(n=1024)$ and $57.8 \%$ rasagiline users $(n=583)$ were men $(P=0.001)$ [50].

(3) Race. The effect of patients' race on the prescription and general utilisation of PD medications was only evaluated in the US-based studies. These studies found that, in inpatient and community settings, African American PD patients were less likely to use dopaminergic medications, especially the newer PD medications; prescribed less PD medications; and prescribed more antipsychotics than white Americans [78, 80, 81]. In nursing home settings, African Americans were less likely to receive PD medications in the USA, but this was not statistically significant $(\mathrm{OR}=0.89,95 \% \mathrm{CI}$ 0.79-1.01) [83]. Another study found that, adding medications that reduce L-dopa-induced motor fluctuations (DAs, MAO-B inhibitors, COMT inhibitors, and amantadine) was more common in non-Hispanic white people when compared with African Americans, although this finding was not statistically significant [82].

(4) Duration of the Disease. Some studies measured the duration of the disease as a prescribing determinant. The use of multiple PD medications was positively associated with the duration of the disease in two studies [55, 73]. Another study used data from a clinical trial of creatine versus placebo in participants with early, mild PD (NET-PD LS1) and found that the number of years since $\mathrm{PD}$ diagnosis was lower in L-dopa monotherapy users than DAs monotherapy users (1.45 years vs 1.60 years, respectively, $P=0.02$ ) [49]. 


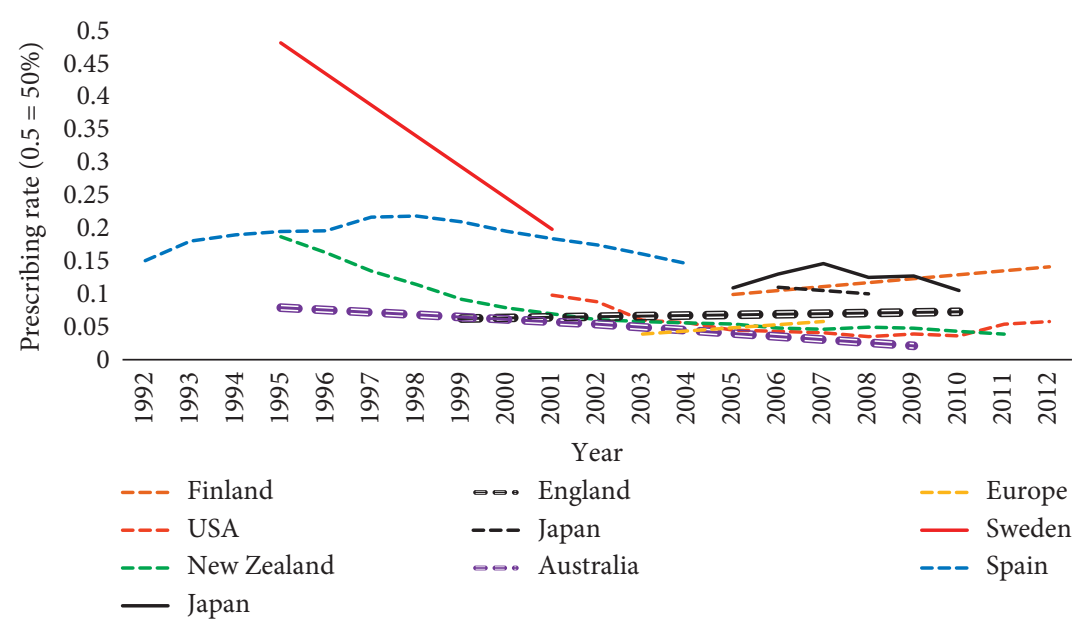

(a)

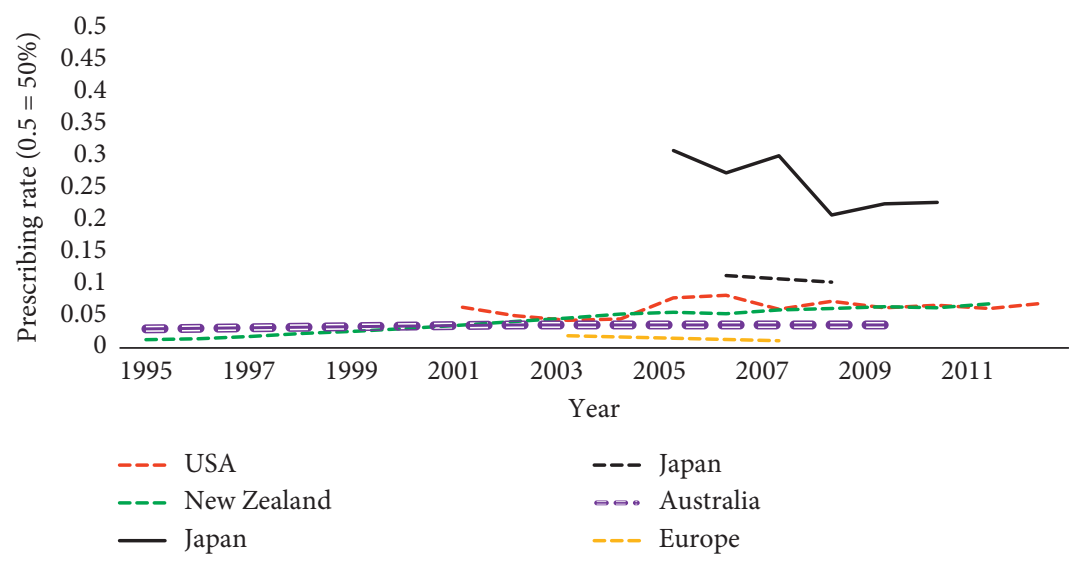

(b)

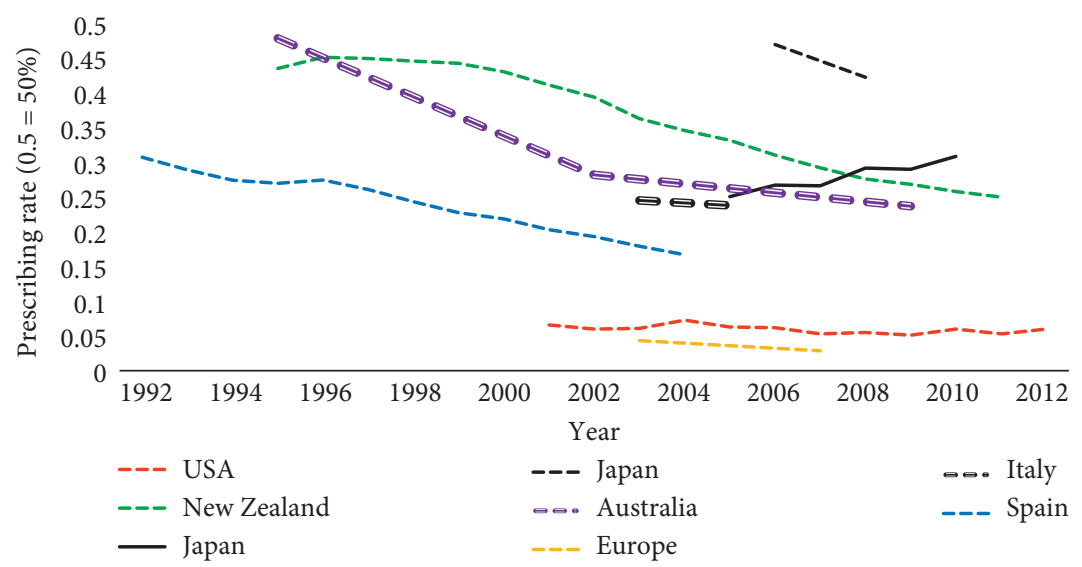

(c)

FIgure 5: Prescribing trends of PD medications. (a) MAO-B inhibitors. (b) Amantadine. (c) Anticholinergics.

(5) Comorbidities. Dahodwala et al. found that patients with high morbidity scores (prescription drug hierarchical condition category (RxHCC) risk score) were less likely to receive multiple $\mathrm{PD}$ medications $(\mathrm{OR}=0.53$, 95\% CI $0.49-0.57, P \leq 0.001$ ) [45]. Different results were observed in another American study that conducted a logistic regression to find the effect of total comorbidity scores on the chance of receiving single or multiple $\mathrm{PD}$ medications in elderly $\mathrm{PD}$
Medicare beneficiaries [64]. The study found no association between PD medications use and the total comorbidity score of patients [64]. However, the same study found that some specific types of comorbidities might have an impact on the chance of receiving single or multiple PD medications. For example, patients with depression were more likely to receive PD medications than nondepressed patients $(\mathrm{OR}=1.25,95 \%$ CI $1.02-1.53, \quad P \leq 0.05) \quad$ [64]. On the 
contrary, patients with dementia were less likely to receive $\mathrm{PD}$ medications than nondementia patients $(\mathrm{OR}=0.62,95 \%$ CI $0.48-0.80, P \leq 0.001$ ) [64]. Similar findings were observed in nursing home setting in the USA where patients with severe cognitive impairment were less likely to receive PD medications than patients with normal cognitive functions $(\mathrm{OR}=0.79,95 \%$ CI $0.73-0.85)$ [83]. Also, another study found that patients with dementia were prescribed anticholinergics as initial therapy more commonly than nondementia patients, but this finding was not statistically significant $(P=0.11)$ [68]. Another study revealed that the addition of medications that reduce L-dopa-induced motor fluctuations was significantly more common in patients with a high comorbidity score (Charlson Index of 5 or more) $(P=0.03)[82]$.

(6) Socioeconomic Status and Care Settings. All the studies that examined the effect of socioeconomic status (SES) on PD drug utilisation were conducted in the USA and they reported conflicting results. Yacoubian et al. failed to find an association between PD medication use and educational level, income, and geographical residence of the patients [80]. Another study found no association between PD medication use and income and marital status of the patient [64]. However, the same study revealed that the chance of being prescribed any of the PD medications was higher for patients with a higher education level (high diploma or more) than patients with a lower education level patients $(\mathrm{OR}=1.51,95 \%$ CI 1.04-2.19; $P<0.05)$ [64]. Hemming et al. found no difference in the use of PD medications across patients with different levels of income and educational level except for the fact that these with lower income and/or a low education level were less likely to be prescribed newer PD medications and were more likely to be prescribed antipsychotics [78]. Another study found that patients with a higher education level were prescribed DAs more often than patients with a lower education level [49]. With regard to the effect of health insurance on prescriptions, one study carried out in the USA confirmed that PD patients without health insurance received fewer PD medications than patients who had health insurance of any type $(P=0.0011)$ [80].

Regarding patients' care settings, an American study found that only $44 \%$ of a total of 24,402 nursing home residents with PD in the USA received PD medications [83]. Another US study based on Medicare claims for PD patients from 2000 to 2003 revealed that patients residing in institutions were more likely to receive $\mathrm{PD}$ medications than residents within the community $(\mathrm{OR}=1.78,95 \%$ CI 1.17 2.71; $P<0.01)$ [64]. The same study found that patients residing in institutions were less commonly prescribed DAs than residents within the community $(15.7 \%$ vs $35 \%$, respectively) $(P<0.001$ [64]. In the UK, Hand et al. compared $\mathrm{PD}$ medication use in the community vs care homes in a retrospective study using The Northumbria Healthcare NHS Foundation Trust PD service in England [48]. They found that the L-dopa equivalent daily dose (LEDD) prescribed to care home residents was lower (median LEDD $=400 \mathrm{mg}$, 95\% IQR 250-610) than that prescribed to the patients in the community (median LEDD $=657.5 \mathrm{mg}$, 95\% IQR 447.5-
1048) $(P<0.001)[48]$. The same study found that use of DAs, MAO-b inhibitors, and COMT inhibitors was higher in patients living in their homes [48].

(7) Geographical Location. This factor has been examined only in one Norwegian study that found that patients who live in Rogaland county were prescribed significantly more L-dopa intestinal gel than other counties in Norway [41]. This difference was attributed in the study to the amount of knowledge patients had about the advanced therapy options in Norway [41].

\subsubsection{Prescribers' Factors}

(1) Type of Prescriber. Eleven studies examined the association between prescriber type and prescribing pattern of $\mathrm{PD}$ medications [45, 56, 59, 62, 63, 68, 70-72, 76, 82]. Prescribers in these studies could be classified as general practitioners (GPs), family physicians, mental health providers, geriatricians, neurologists, and movement disorders specialists.

A US survey evaluating 54 family physicians, 328 neurologists, and 74 movement disorder specialists, determined that half of the family physicians and almost one-third of the neurologists prescribe L-dopa as a starting therapy for PD patients immediately after diagnosis [59]. While in Spain, no significant difference was found in the percentages of prescribers of L-dopa among family physicians, geriatricians, neurologists, and movement disorder specialists (87.3\%, $86.1 \%, 91.2 \%, 91.9 \%$, respectively) [71] although movement disorders specialists tended to prescribe DAs more often and exclusively prescribed amantadine [71]. In USA, family physicians were more likely to prescribe L-dopa, while neurologists and movement disorder specialists were more likely to prescribe DAs [68]. Likewise, in Australia, around $80 \%$ of the total DID of L-dopa was prescribed by family physicians while $10 \%$ to $20 \%$ was prescribed by neurologists with minimal variation between 2003 and 2009 [62].

In the USA, mental health providers were more likely to prescribe anticholinergics as an initial therapy than other prescribers $(\mathrm{OR}=76,95 \%$ CI 31.7-181.7) [68], whilst in Spain, the percentage of patients treated with anticholinergics was higher if they were treated by family physicians $(17.8 \%)$ as opposed to geriatricians (11.1\%), neurologists (8.6\%), or movement disorder specialists (7\%) [71].

Polytherapy and therapy switching were another two issues that only a few studies examined. In USA, Dahodwala et al. found that patients who were treated by neurologists were more likely to receive multiple PD medications than patients who were treated by others (non-neurologists) [45]. In a study in Taiwan that examined the type of initial therapy in PD patients from 2000 to 2010, it was found that $79.3 \%$ of L-dopa and DAs combination therapy was initiated by neurologists and $20.7 \%$ was initiated by non-neurologists [56]. The same study noted that patients who were treated by neurologists were more likely to be switched to another drug within one year of the study [56].

The impact of the type of prescriber on adherence to national guidelines was another parameter that was evaluated in two studies $[63,76]$. The French study failed to find a 
significant difference between neurologists and non-neurologists in adherence to the type of initial therapy that was recommended in French treatment guidelines of PD in 2000 [63]. Conversely, the Chinese study found that movement disorders specialists were more successful than GPs and general neurologists in improving a patient's quality of care and adhering to Chinese national guidelines that included several recommendations on how to reduce L-dopa-induced motor fluctuations by adding COMT inhibitors, MAO-B inhibitors, or others [76]. Likewise, Cheng et al. found that prescribing medications that reduced L-dopa-induced motor fluctuations was more commonly done by movement disorders specialists than general neurologists and GPs in the USA [82].

\section{Discussion}

The number of PD-related drug utilisation studies identified for review in this study was limited, taking into account the non-negligible prevalence of PD $[85,86]$. Most of the studies that were included were conducted in the USA and Europe (68\% of all studies) which have limited the geographical spread. This may relate to the high prevalence of PD cases in these countries, exemplified by a recent meta-analysis examining 47 prevalence studies globally, determining that PD prevalence was higher across all ages in Europe, North America, and Australia than in Asia [85]. However, in terms of prevalence, South America surpassed them all [85] but no drug utilisation study in South America was identified for review.

The source of drug utilisation data varied in the reviewed studies, with $38 \%$ of the data being sourced from insuranceclaim, prescription registry, or drug sales databases. Data sourced from insurance-claims or similar sources may include a large number of patients which makes it possible to generalise the study results to the whole population but it is also highly possible that these databases include patients who have other diseases that have mistakenly been diagnosed as PD (e.g., secondary parkinsonism) since these data lack detailed patient clinical information. Several studies that used this source of data that were included in this review acknowledged this drawback and considered the possibility of over estimation of PD medication prescribing rates $[45,46,54,56,64,81,83]$. About $26 \%$ of the studies reviewed here used patient interviews, questionnaires, and surveys to estimate drug utilisation rates. Although this approach might give a more accurate estimate of medication prescribing patterns, given that the data are based on a more accurate diagnosis by PD experts [43, 44, 63], the relatively small sample sizes restricts the generalisability of the findings. Use of electronic medical records (EMRs) and GP data may overcome the problems of small sample size and misdiagnosis in drug utilisation studies. However, to avoid the inherent drawbacks of EMR (missing data and data entry errors), it is essential to validate these electronic medical records against standard criteria such as the actual paper files of the patients, GP questionnaires, or linking data to other databases $[87,88]$. Of all the studies that used EMR and GP data included in this review (28\%), none were validated against standard criteria. However, in general, the impact of source of data on PD medications prescribing was minimal in most studies. The exception was L-dopa which was reportedly more prescribed than other PD medications in studies using interviews, questionnaires, and surveys in their methodology. However, this increase is most likely due to the time of these studies (most of them were conducted before 2000), when the current portfolio of dopaminergic drugs was either not clinically available or efficacy was not well-established (Part 5 in Supplementary Materials). Therefore, no valid conclusion could be drawn from a simple comparison of L-dopa prescribing according to the source of data.

In the majority of studies, regardless of the study year or location, unsurprisingly L-dopa plus a dopa decarboxylase inhibitor (carbidopa or benserazide) persists as the most commonly prescribed PD medication, (with or without the COMT inhibitor, entacapone), with no significant changes over time. Where an increase was identified over time (New Zealand, Australia, Sweden, and Spain) [53, 62, 67, 72], this was hypothesised to be due to an increase in PD incidence, an increase in the duration of the disease, or an increasing preference for L-dopa therapy over DAs in the early stages of the disease. Determining which cannot be identified from this data but a real increased PD incidence is unlikely. We had anticipated that some trends might have evidenced the changing recommendations in DA vs L-dopa use. In the early 2000s, multiple studies reported that long-term L-dopa could contribute to neurotoxicity $[89,90]$. The ELLDOPA trial in 2004 [91] refuted these findings, and the American Academy of Neurology (AAN) guidelines in 2006 used this evidence to state that L-dopa did not accelerate disease progression [92]. There was vigorous debate in the field at this time on the benefits of commencing therapy with DA agonists to delay onset of L-dopa-induced dyskinesia (LID) and other potential benefits of reduced development of LID we anticipated might have altered prescribing but this was only evident in marginal trends $[93,94]$. Recently, the LEAP study revealed that L-dopa has no disease-modifying effects [95]; however, the high reliance on L-dopa could be explained by its higher efficacy and better safety profile than other PD medications $[96,97]$. Indeed, the PD-MED study only supported part of this rational used the QoL scale and determining that initiating patients with L-dopa actually resulted in a better QoL than using DAs and that reducing motor fluctuations by delaying L-dopa initiation was not associated with better results over the long term [32].

In this review, there was a noticeable paucity of studies examining the prescribing of advanced infusion therapies in advanced PD patients. For LCIG, there was only one study that examined its prescribing rates in advanced stages of $P D$ [41]. LCIG is an intestinal infusion pump, which aims to avoid the motor complications caused by oral L-dopa, by offering more continuous dopaminergic stimulation and constant levels of plasma levodopa [17]. However, the promising efficacy of LCIG [17] and its improvement to QOL [98] could be hindered by the high cost, invasive nature of the LCIG pump, and possible complications at the infusion site [17]. Therefore, it is of importance to investigate 
the actual pharmacoepidemiological use of this kind of therapy and the factors that determine its prescribing in future research. It is of importance also to conduct more research on the prescribing of the second type of advanced therapy, apomorphine, since very few studies identified report its prescribing, and those that do fail to specify its pharmaceutical forms.

Early reports of potential neuroprotective effects of DAs may have contributed to a general increase in DAs prescribing in the early 2000s [99-103], but in 2006, the AAN report stated that there was no evidence of neuroprotection for DAs [92] and subsequent reports and clinical trials confirmed the AAN recommendation [17, 20, 22, 103, 104]. These reports might explain why some studies found a slight decrease in the prescription of DAs especially after 2005 $[51,54]$. The slight increase or consistent rate in prescribing DAs is seen in other studies $[47,53,56,61,62]$ which might be due to the fact that DAs were still the recommended treatment in the guidelines as a starting therapy especially with younger patients [105-107]. Recently, the UK NICE guidelines recommended starting therapy with DAs or other dopaminergic therapies (MAO-B inhibitors or L-dopa) in the early stages of PD if the motor symptoms do not impact patients' quality of life [108].

Within the subtypes of the DAs, several cross-sectional studies have shown a wide range of ergot DAs prescription rates. The relatively high prescribing rate seen in the studies conducted before 2000, may be due to the cumulative effect of reports of L-dopa neurotoxicity in the late 1990s and early 2000s $[89,90]$, the hope that ergot DAs might possess neuroprotective properties $[102,109,110]$, and the fact that ergot DAs side effects, such as cardiac fibrosis, had not yet been discovered. In the trend studies, most showed a decrease in the prescription of ergots even though the results of a large-scale UK study that led to a voluntary withdrawal of this drug from the US and Canadian markets in 2007 had not yet been published $[111,112]$. For example, in the USA, there was a $5.1 \%$ decrease in the prescription of ergots between 2001 and 2007 [51]. The same phenomenon was seen in New Zealand, Japan, Italy, and Spain, in parallel with an increase in non-ergot DAs prescription $[53,54,66,71]$. An association between the use of ergot DAs (pergolide initially) and valvular heart toxicity was reported in the early 2000s [113]. Whilst non-ergot DAs might have seemed an obvious alternative, reports then emerged of side effects associated with their use [114-118]. Although in several studies the non-ergot prescription rate increased, particularly after pergolide withdrawal $[46,47,51,53,54,62]$, the prescription rates decreased in the USA in 2011 [51]. This could be explained by reports of several side effects of non-ergot DAs that appeared between 2006 and 2017. Examples of these side effects, in addition to reports of the risk of heart failure associated with pramipexole, include ICDs [119]. ICDs in this context are typified by a failure to resist the urge for sexual intercourse, gambling, and eating, and it is evident from the DOMINION study that ICDs are significantly associated with DAs [120]. It is disappointing that, despite the increase in recognition ICDs among DAs users, most studies conducted in the last 10 years did not mention the impact of ICDs on DAs prescribing. It will be important to conduct further studies to explicitly examine whether increased awareness of ICDs among prescribers and patients has had an effect on their prescribing.

Prescribing rates of COMT inhibitors were largely consistent with both slight increase $[51,53,54]$ and slight decrease $[62,65,67]$ reported. In some studies, differentiating the exact prescription rate of COMT inhibitors without considering the $\mathrm{L}$-dopa prescription rate is difficult since the prescription rate of the L-dopa + carbidopa + entacapone combination was reported in the studies but not the rate of entacapone alone $[45,47,51,57,58,60,64,65]$. Tolcapone monotherapy was explicitly measured in one study in Italy in 1997-1998 and showed a very low prescription rate $(1.3 \%$ of the total prescriptions) [73] which is likely linked to the FDA black box warning about the hepatotoxicity risk in 1998 [121] and its very recent approval. Post 2000, any increase in entacapone plus tolcapone prescription rates as in the USA [51] and New Zealand [53] might have been due to entacapone alone since tolcapone prescriptions were restricted due to its hepatotoxicity. No conclusion could be drawn regarding the prescription rates of the L-dopa + carbidopa + entacapone combination in a number of the studies which did not distinguish between its prescription rate and the L-dopa + carbidopa combinations prescription rate $[45,47,51,57,58,60,64,65]$.

Although it was still in clinical trials testing for possible neuroprotective properties after its approval in 2006, the prescription rate for rasagiline (an MAO-B inhibitor) was only examined in six of the studies $[47,48,51,55,58,65]$ whilst the prescription rate for selegiline was highly varied between studies $[53,54,57,60-62,64,67-73,75,83,84]$. The decrease in prescribing around 1995 can be linked to the PDRG-UK trial which suggested association with an increased mortality rate [122], although was subsequently debated by a meta-analysis [123]. Furthermore the decline in use has continued with the purported neuroprotective properties suggested by a range of clinical trials (TEMPO [18], ADAGIO [19]) being unsupported by the guidance [108]. Safinamide is an MAO-B inhibitor that has been recently approved as an add-on therapy to L-dopa in patients who develop motor fluctuations and with its relatively recent appearance its place on the $\mathrm{PD}$ stage has yet to evolve significantly.

A huge variation in amantadine prescription rates can be seen, which is characterised by very low and consistent rates in all but Japan for which there is no explanation [54]. Unlike other PD medications, amantadine has not been subjected to significant changes in safety or efficacy profiles since the Schwab trail in 1969 that suggested the clinical efficacy of amantadine in treating PD symptoms [3]. The main indication for amantadine, based on Schwab's work, was to treat the early symptoms of PD, but this was not enough to avoid adding or switching to L-dopa therapy in the long run [124]. In the late 1990s, several studies showed the antidyskinetic effect of amantadine to treat L-dopa-induced dyskinesia $[125,126]$. In 2017, the extended release form of amantadine was the first medication that was approved by the US FDA to treat L-dopa-induced dyskinesia 
[127]. How this formulation and approval affects prescribing remains to be seen moving forward.

Anticholinergics were routinely used in the treatment of PD before the discovery of L-dopa; however, due to their troublesome side effects, their use is limited at present to managing severe tremor in younger patients who do not suffer from cognitive problems [128]. Notwithstanding this fact, anticholinergic prescription rates were generally high in most Asian studies [42, 43, 54, 55, 61, 70] but is generally reducing over time through replacement with other strategies. This was explained, for example, in one Japanese study by the fact that the treatment guidelines in Japan in the early 2000s recommended anticholinergics as the first option [54]. An Indian study attributed this high rate of prescribing anticholinergics to the fact that they were cheaper than most of the other PD medications in India [43]. In the USA, two cross-sectional studies showed a very low rate of anticholinergics prescriptions possibly reflecting an awareness of anticholinergics side effects especially in older patients $[45,64]$. Conversely, Lapane et al. found a high rate of anticholinergics prescriptions $(18.18 \%)$ in nursing home settings in the USA [83]. These data are confounded by the use of anticholinergics in neuroleptic-induced parkinsonism and other conditions.

4.1. Prescribing Determinants. Age was one of the most common factors that affects the use of PD medications. In a number of studies, older patients were less likely to receive PD medications than younger patients, likely to be linked to fear of side effects, interactions, or increased morbidity. This is consistent with findings that old age in general has a positive association with high morbidity scores in people with Parkinson's [129].

Whilst L-DOPA has been demonstrated to be the most effective medication for all age groups in PD [130], several studies demonstrated a clear preference for younger patients to be prescribed DA agonists, withdrawing them in older people, consistent with the guidelines. L-dopa causes fewer side effects than DAs in elderly people [131] and DAs are three times more likely to cause hallucinations than L-dopa $[132,133]$. Additionally, DAs cause a higher rate of somnolence and sleep attacks $[132,133]$ and could significantly more likely trigger ICDs such as hypersexuality and pathological gambling $[134,135]$. However, notwithstanding these recommendations, Cirspo et al. found that, in inpatient settings in the USA, there was a continuous high rate of prescription of DAs for elderly patients, which raised a question regarding the awareness of treatment guidelines [51]. In relation to the L-dopa dose given, a Swedish study found that older patients were associated with a lower L-dopa dose than younger patients [79] which may be due to the pharmacokinetics (L-dopa has a greater bioavailability and less clearance volume in elderly people $[136,137])$.

Overall, according to the studies included in this review, it seems that the several guidelines published after 2000 $[28,107,138]$ recommending starting therapy with DAs or $\mathrm{MAO}-\mathrm{B}$ inhibitors in younger patients and starting L-dopa in older patients might have had an impact on clinical practice. However, according to the results of the PD-MED study, the recent NICE guidelines did not consider age as a factor in choosing the first-line treatment. Patients' quality of life, instead, was the major factor that affected the treatment decision. According to the NICE guidelines, if motor symptoms do not affect patients' quality of life, then starting therapy with DAs or other dopaminergic therapies (MAO-B inhibitors or L-dopa) is recommended [108]. L-dopa, on the contrary, should be used if motor symptoms affect the patients' quality of life [109].

Gender was examined in multiple studies but with conflicting outcomes. Whilst several studies found no gender relationship in L-dopa and DAs prescription rates $[51,52,64,66,69]$, others found that women had lower odds of being prescribed L-dopa [45], were less likely to receive PD medications (both polytherapy and monotherapy) $[45,80,83]$, and the L-dopa daily dose was lower for women [79]. Whilst this may be linked to the pharmacokinetics, this is under research and does require more investigation into the differences in responses between medications and sensitivity to side effects.

In most countries, the patients' race was not investigated as a factor influencing prescription. However, a few studies in USA revealed inequalities relating to African Americans when it comes to PD medication prescriptions, particularly with regard to the newly approved medications, which are generally more expensive [78, 80-83]. Similar inequalities exist across broad tranches of the US healthcare system in relation to PD $[139,140]$ and other conditions which may be linked to African Americans in general are less likely to have medical insurance and have less access to healthcare facilities than white Americans in the USA [141].

Residence in long-term care facilities such as care homes can be a factor affecting access to health care in PD patients. One study, that included a large number of PD patients in care home settings in the USA, found that about $56 \%$ of patients did not receive any PD medication [83]. The study did not consider this phenomenon as a sign of health inequality; rather, it suggested that these patients had most likely been admitted to nursing homes due to debilitating side effects, i.e., psychosis caused by PD medications. This claim was supported by Hand et al. who compared PD medication use in the community vs care homes in England and found that LEDD was lower in care home residents than patients in the community [48]. Although there is a difference in the endpoints of the two previous studies, i.e., the first study examined any single use of PD medication [83] while the second measured the total dose of PD medications taken [48], both reached the same conclusion. According to the two studies, the reason behind the lower use or lower dose of PD medications in care homes was to avoid psychotic episodes caused by PD medication. In PD patients, psychosis can occur as a consequence of the disease itself, or it can be caused by the PD medications [142]. Thus, it is crucial, when managing psychosis in PD patients, to titrate firstly the PD medication doses before considering prescribing antipsychotics [143]. Despite previous evidence that attributed the lack of PD medication utilisation in care homes to a plausible clinical reason, i.e., to avoid the side 
effects of PD medications, some studies found inappropriate management for PD patients in care homes $[83,144]$. This could be explained by lack of access to secondary clinics or switching to a new GP which resulted in suboptimal care [145]. Telemedicine (the approach that uses new technology such as video teleconferencing to link health care providers to PD patients directly) is one tool that could potentially resolve the issue of lacking access to health care due to difficulty accessing health care facilities [146].

Among the countries covered in this review, there were differences in health care systems, prescribing guidelines and in the eligibility of the patients, which limit the value of making comparisons between countries. However, there were some common observations that are worth mentioning in relation to the prescribers themselves. In the only studies identified, movement disorders specialists and neurologists, more than family physicians or GPs, were more likely to prescribe DAs according to some of the studies $[62,68,71]$, whereas family physicians and GPs were more likely to prescribe L-dopa or anticholinergics $[62,71]$. Since these studies predate many of the changes in guidance, more upto-date examination of the relative roles and trends in prescribing would be valid.

This study has several limitations. First, the reviewed studies were heterogeneous in terms of design, duration, and data sources. This makes direct comparisons of the prescription rates of different PD medications very difficult. This type of difficulty has been previously identified in other studies [147, 148]. Second, although quality scores were assigned to each study, no study was excluded on the basis of its quality score due to lack of evidence. However, the study score might indicate its quality level. Future studies should focus on developing a quality assessment tool that would help researchers make decisions in drug utilisation research. Third, the fact that this review included only English studies could introduce language bias. However, we tried to minimize this bias by identifying relevant non-English-language studies in our literature searches. The fourth limitation was the assumption that has been made in the discussion section which has attributed the changes in prescribing patterns of PD medication to awareness or nonawareness of the guidelines. Other factors such as drug availability and patient preferences might explain some prescribing behaviours. Therefore, caution should be taken when interpreting the results reported in this review.

\section{Conclusions}

In conclusion, worldwide, since the discovery of L-dopa, it has been the most commonly prescribed PD medication. The prescription rates of ergot-derived DAs decreased in several countries due to cardiac toxicity issues, while the use of nonergot DAs increased. Significant country to country variation in the prescribing rates of COMT inhibitors, MAO-B inhibitors, amantadine, and anticholinergics was found. Alongside this, patient age was the most common factor that affected prescribing in most studies. The most recent $3^{\text {rd }}$ generation MAO and COMT inhibitors have not been considered in any study as they are so new to the portfolio and new guidance has recently been released in the UK.

\section{Conflicts of Interest}

The authors declare that there are no conflicts of interest regarding the publication of this paper.

\section{Acknowledgments}

This research was funded by a scholarship from King Khalid University (KKU) in Saudi Arabia supporting KO to undertake a PhD at Cardiff University, UK.

\section{Supplementary Materials}

Part 1 in the supplementary data shows the search methods for the identification of prescribing pattern studies for antiparkinsonian agents using the following databases (EMBASE, MEDLINE, and PsycINFO). Then, Part 2 shows a PRISMA flow chart for systematic research of prescribing patterns and determinants in non-English-language studies. Next, Part 3 shows a summary of the studies that examined the prescribing patterns of PD medications in non-Englishlanguage studies, and Part 4 shows details of the Joanna Briggs Institute Critical Appraisal Tool for Use in Prevalence Studies. Part 5 shows a figure of differences in the prescribing pattern of PD medications according to the quality scores of the studies and data sources. Part 6 shows the quality scores resulting from the Joanna Briggs Institute Critical Appraisal Tool. Finally, Part 7 shows the prescription rates of PD medications in the studies of this review. (Supplementary Materials)

\section{References}

[1] G. C. Cotzias, M. H. Van Woert, and L. M. Schiffer, "Aromatic amino acids and modification of parkinsonism," New England Journal of Medicine, vol. 276, no. 7, pp. 374-379, 1967.

[2] A. J. Lees, E. Tolosa, and C. W. Olanow, "Four pioneers of L-dopa treatment: Arvid Carlsson, Oleh Hornykiewicz, George Cotzias, and Melvin Yahr," Movement Disorders, vol. 30, no. 1, pp. 19-36, 2015.

[3] R. S. Schwab, A. C. England Jr., D. C. Poskanzer, and R. R. Young, "Amantadine in the treatment of Parkinson's disease," JAMA: The Journal of the American Medical Association, vol. 208, no. 7, pp. 1168-1170, 1969.

[4] S. Fahn, "The spectrum of levodopa-induced dyskinesias," Annals of Neurology, vol. 47, no. 1, pp. S2-S11, 2000.

[5] C. W. Olanow, "Can we achieve neuroprotection with currently available anti-parkinsonian interventions?," Neurology, vol. 72, no. 7, pp. S59-S64, 2009.

[6] D. B. Calne, P. F. Teychenne, L. E. Claveria, R. Eastman, J. K. Greenacre, and A. Petrie, "Bromocriptine in Parkinsonism," BMJ, vol. 4, no. 5942, pp. 442-444, 1974.

[7] W. Birkmayer, W. Linauer, M. Mentasti, and P. Riederer, "2year experiences with a combination treatment of Parkinsonism with L-dopa and a decarboxylase inhibitor (Benserazid, Ro 4-4602)," Wiener Medizinische Wochenschrift, vol. 124, no. 22, pp. 340-344, 1974. 
[8] R. D. Sweet, F. H. McDowell, C. G. Wasterlain, and P. H. Stern, "Treatment of "On-Off effect" with a dopa decarboxylase inhibitor," Archives of Neurology, vol. 32, no. 8 , pp. $560-563,1975$.

[9] S. Fahn, "The history of dopamine and levodopa in the treatment of Parkinson's disease," Movement Disorders, vol. 23, no. 3, pp. S497-S508, 2008.

[10] J. Knoll, "History of deprenyl--the first selective inhibitor of monoamine oxidase type B," Voprosy Meditsinskoi Khimii, vol. 43, no. 6, pp. 482-493, 1997.

[11] E. Tolosa, M. J. Marti, F. Valldeoriola, and J. L. Molinuevo, "History of levodopa and dopamine agonists in Parkinson's disease treatment," Neurology, vol. 50, no. 6, pp. S2-S10, 1998.

[12] P. T. Mannisto and S. Kaakkola, "Catechol-O-methyltransferase (COMT): biochemistry, molecular biology, pharmacology, and clinical efficacy of the new selective COMT inhibitors," Pharmacological Reviews, vol. 51, no. 4, pp. 593-628, 1999.

[13] C.-Q. Zhou, S.-S. Li, Z.-M. Chen, F.-Q. Li, P. Lei, and G.-G. Peng, "Rotigotine transdermal patch in Parkinson's disease: a systematic review and meta-analysis," PLoS One, vol. 8, no. 7, Article ID e69738, 2013.

[14] P. L. McCormack, "Rasagiline: a review of its use in the treatment of idiopathic Parkinson's disease," CNS Drugs, vol. 28, no. 11, pp. 1083-1097, 2014.

[15] L. J. Scott, "Opicapone: a review in Parkinson's disease," Drugs, vol. 76, no. 13, pp. 1293-1300, 2016.

[16] H. A. Blair and S. Dhillon, "Safinamide: a review in Parkinson's disease," CNS Drugs, vol. 31, no. 2, pp. 169-176, 2017.

[17] S. Varanese, Z. Birnbaum, R. Rossi, and A. Di Rocco, "Treatment of advanced Parkinson's disease," Parkinson's Disease, vol. 2010, Article ID 480260, p. 9, 2010.

[18] R. Katzenschlager, J. Head, A. Schrag et al., "Fourteen-year final report of the randomized PDRG-UK trial comparing three initial treatments in PD," Neurology, vol. 71, no. 7, pp. 474-480, 2008.

[19] R. A. Hauser, M. F. Lew, H. I. Hurtig et al., "Long-term outcome of early versus delayed rasagiline treatment in early Parkinson's disease," Movement Disorders, vol. 24, no. 4, pp. 564-573, 2009.

[20] C. W. Olanow, O. Rascol, R. Hauser et al., "A double-blind, delayed-start trial of rasagiline in Parkinson's disease," New England Journal of Medicine, vol. 361, no. 13, pp. 1268-1278, 2009.

[21] R. Holloway, K. Marek, K. Biglan et al., "Long-term effect of initiating pramipexole vs levodopa in early Parkinson disease," Archives of Neurology, vol. 66, no. 5, pp. 563-570, 2009.

[22] A. H. V. Schapira, "Monoamine oxidase B inhibitors for the treatment of Parkinson's disease," CNS Drugs, vol. 25, no. 12, pp. 1061-1071, 2011.

[23] A. H. Schapira, M. P. McDermott, P. Barone et al., "Pramipexole in patients with early Parkinson's disease (PROUD): a randomised delayed-start trial," The Lancet Neurology, vol. 12, no. 8, pp. 747-755, 2013.

[24] M. A. Hely, J. G. Morris, D. Rail et al., "The Sydney Multicentre Study of Parkinson's disease: a report on the first 3 years," Journal of Neurology, Neurosurgery and Psychiatry, vol. 52, no. 3, pp. 324-328, 1989.

[25] U. K. Rinne, F. Bracco, C. Chouza et al., "Early treatment of Parkinson's disease with cabergoline delays the onset of motor complications. Results of a double-blind levodopa controlled trial," Drugs, vol. 55, no. 1, pp. 23-30, 1998.
[26] Parkinson Study Group, "Pramipexole vs. levodopa as initial treatment for Parkinson disease," JAMA, vol. 284, no. 15, pp. 1931-1938, 2000.

[27] O. Rascol, D. J. Brooks, A. D. Korczyn, P. P. De Deyn, C. E. Clarke, and A. E. Lang, "A five-year study of the incidence of dyskinesia in patients with early Parkinson's disease who were treated with ropinirole or levodopa," New England Journal of Medicine, vol. 342, no. 20, pp. 1484-1491, 2000.

[28] F. Bracco, A. Battaglia, C. Chouza et al., "The long-acting dopamine receptor agonist cabergoline in early Parkinson's disease," CNS Drugs, vol. 18, no. 11, pp. 733-746, 2004.

[29] C. W. Olanow, R. L. Watts, and W. C. Koller, "An algorithm (decision tree) for the management of Parkinson's disease (2001): treatment guidelines," Neurology, vol. 56, no. 6, pp. S1-S88, 2001.

[30] J. M. Miyasaki, W. Martin, O. Suchowersky, W. J. Weiner, and A. E. Lang, "Practice parameter: initiation of treatment for Parkinson's disease: an evidence-based review: report of the Quality Standards Subcommittee of the American Academy of Neurology," Neurology, vol. 58, no. 1, pp. 11-17, 2002.

[31] F. Blandini and M.-T. Armentero, "Dopamine receptor agonists for Parkinson's disease," Expert Opinion on Investigational Drugs, vol. 23, no. 3, pp. 387-410, 2014.

[32] National Collaborating Centre for Chronic Conditions, Parkinson's Disease, National Clinical Guideline for Diagnosis and Management in Primary and Secondary Care, Royal College of Physicians, London, UK, 2006.

[33] PD MED Collaborative Group, "Long-term effectiveness of dopamine agonists and monoamine oxidase B inhibitors compared with levodopa as initial treatment for Parkinson's disease (PD MED): a large, open-label, pragmatic randomised trial," The Lancet, vol. 384, no. 9949, pp. 1196-1205, 2014.

[34] S. Jain, P. Jain, V. Moghe et al., "A systematic review of prescription pattern monitoring studies and their effectiveness in promoting rational use of medicines," Perspectives in Clinical Research, vol. 6, no. 2, pp. 86-90, 2015.

[35] E. von Elm, D. G. Altman, M. Egger, S. J. Pocock, P. C. Gøtzsche, and J. P. Vandenbroucke, "The Strengthening the Reporting of Observational Studies in Epidemiology (STROBE) statement: guidelines for reporting observational studies," Journal of Clinical Epidemiology, vol. 61, no. 4, pp. 344-349, 2008.

[36] https://www.nhlbi.nih.gov/health-topics/study-quality-assess ment-tools.

[37] G. A. Neyarapally, T. A. Hammad, S. P. Pinheiro, and S. Iyasu, "Review of quality assessment tools for the evaluation of pharmacoepidemiological safety studies," $B M J$ Open, vol. 2, no. 5, Article ID e001362, 2012.

[38] Z. Munn, S. Moola, D. Riitano, and K. Lisy, "The development of a critical appraisal tool for use in systematic reviews addressing questions of prevalence," International Journal of Health Policy and Management, vol. 3, no. 3, pp. 123-128, 2014.

[39] J. Pedro-Cuesta, I. J. Petersen, D. Vassilopoulos, F. Micheli, and A. Garcia-Inesta, "Epidemiological assessment of levodopa use by populations," Acta Neurologica Scandinavica, vol. 83, no. 5, pp. 328-335, 1991.

[40] B. C. L. Lai, M. Schulzer, S. Marion, K. Teschke, and J. K. C. Tsui, “The prevalence of Parkinson's disease in British Columbia, Canada, estimated by using drug tracer 
methodology," Parkinsonism and Related Disorders, vol. 9, no. 4, pp. 233-238, 2003.

[41] B. Ezat, L. Pihlstrøm, J. Aasly, O.-B. Tysnes, A. Egge, and E. Dietrichs, "Bruk av avansert behandling ved Parkinsons sykdom i Norge," Tidsskrift for Den Norske Legeforening, vol. 137, no. 9, pp. 619-623, 2017.

[42] R. K. Tripathi, S. V. Kapse, and A. V. Potey, "Prescription pattern and awareness of disease and treatment in patients of Parkinson's disease," Neurodegenerative Disease Management, vol. 7, no. 5, pp. 299-306, 2017.

[43] P. Surathi, N. Kamble, K. S. Bhalsing, R. Yadav, and P. K. Pal, "Prescribing pattern for Parkinson's disease in Indian community before referral to tertiary center," Canadian Journal of Neurological Sciences, vol. 44, no. 6, pp. 1-6, 2017.

[44] W. H. Jost and J. Bausch, "Patients' perspective on current treatment options for Parkinson's Disease," Basal Ganglia, vol. 9, no. 9, pp. 7-11, 2017.

[45] N. Dahodwala, A. W. Willis, P. Li, and J. A. Doshi, "Prevalence and correlates of anti-Parkinson drug use in a nationally representative sample," Movement Disorders Clinical Practice, vol. 4, no. 3, pp. 335-341, 2017.

[46] W. M. Liu, R. M. Wu, C. H. Chang et al., "National trends of antiparkinsonism treatment in Taiwan: 2004-2011," Parkinson's Disease, vol. 2016, Article ID 1859321, 8 pages, 2016.

[47] T. Keränen and L. J. Virta, "Association of guidelines and clinical practice in early Parkinson's disease," European Geriatric Medicine, vol. 7, no. 2, pp. 131-134, 2016.

[48] A. Hand, W. K. Gray, L. L. Oates et al., "Medication use in people with late stage Parkinson's disease and parkinsonism living at home and in institutional care in north-east England: a balance of symptoms and side-effects?," Parkinsonism and Related Disorders, vol. 32, pp. 120-123, 2016.

[49] J. L. Goudreau, A. Pérez, M. J. Aminoff et al., "Choice of dopaminergic therapy among early, mild Parkinson disease subjects in North America," Journal of the Neurological Sciences, vol. 366, pp. 74-81, 2016.

[50] L. Degli Esposti, C. Piccinni, D. Sangiorgi, F. Nobili, and S. Buda, "Prescribing pattern and resource utilization of monoamine oxidase-B inhibitors in Parkinson treatment: comparison between rasagiline and selegiline," Neurological Sciences, vol. 37, no. 2, pp. 227-234, 2016.

[51] J. A. G. Crispo, Y. Fortin, D. P. Thibault et al., "Trends in inpatient antiparkinson drug use in the USA, 2001-2012," European Journal of Clinical Pharmacology, vol. 71, no. 8, pp. 1011-1019, 2015.

[52] C. C. Umeh, A. Pérez, E. F. Augustine et al., "No sex differences in use of dopaminergic medication in early Parkinson disease in the US and Canada-baseline findings of a multicenter trial," PLoS One, vol. 9, no. 12, Article ID e112287, 2014.

[53] T. Pitcher, M. MacAskill, and T. Anderson, "Trends in antiparkinsonian medication use in New Zealand: 19952011," Parkinson's Disease, vol. 2014, Article ID 379431, 9 pages, 2014.

[54] S. Nakaoka, T. Ishizaki, H. Urushihara et al., "Prescribing pattern of anti-Parkinson drugs in Japan: a trend analysis from 2005 to 2010," PLoS One, vol. 9, no. 6, Article ID e99021, 2014.

[55] V. K. Junjaiah, S. Bhimalli, S. Shenoy et al., "A prospective study of the drug prescribing rate and pattern and assessment of adverse drug reactions in patients with idiopathic Parkinson disease in a tertiary care hospital," American Journal of Phytomedicine and Clinical Therapeutics, vol. 2, no. 3, pp. 420-429, 2014.
[56] Y.-J. Guo, Y.-C. Liao, C.-H. Lin, and M.-H. Chang, "Initial medication in patients of newly diagnosed Parkinson's disease in Taiwan," PLoS One, vol. 9, no. 9, Article ID e107465, 2014.

[57] R. Gaida and I. Truter, "Prescribing patterns for Parkinson's disease in a South African patient population," Journal of Applied Pharmaceutical Science, vol. 4, no. 3, pp. 29-34, 2014.

[58] P. Morrish, "Prescribing in Parkinson's disease: a story of hope and adverse events," Practical Neurology, vol. 12, no. 5, pp. 335-340, 2012.

[59] N. Hattori, K. Fujimoto, T. Kondo, M. Ogawa, and M. Stacy, "Patient perspectives on Parkinson\&rsquo;s disease therapy in Japan and the United States: results of two patient surveys," Patient Related Outcome Measures, vol. 3, pp. 31-38, 2012.

[60] S. Schroder, D. Kuessner, G. Arnold et al., "Do neurologists in Germany adhere to the national Parkinson's disease guideline?," Neuropsychiatric Disease and Treatment, vol. 7, pp. 103-110, 2011.

[61] N. Ooba, T. Yamaguchi, and K. Kubota, "The impact in Japan of regulatory action on prescribing of dopamine receptor agonists," Drug Safety, vol. 34, no. 4, pp. 329-338, 2011.

[62] S. A. Hollingworth, A. Rush, W. D. Hall, and M. J. Eadie, "Utilization of anti-Parkinson drugs in Australia: 19952009," Pharmacoepidemiology and Drug Safety, vol. 20, no. 5, pp. 450-456, 2011.

[63] C. Fayard, A. Bonaventure, I. Benatru et al., "Impact of recommendations on the initial therapy of Parkinson's disease: a population-based study in France," Parkinsonism and Related Disorders, vol. 17, no. 7, pp. 543-546, 2011.

[64] Y.-J. J. Wei, B. Stuart, and I. H. Zuckerman, "Use of antiparkinson medications among elderly Medicare beneficiaries with Parkinson's disease," The American Journal of Geriatric Pharmacotherapy, vol. 8, no. 4, pp. 384-394, 2010.

[65] M. M. Rosa, J. J. Ferreira, M. Coelho, R. Freire, and C. Sampaio, "Prescribing patterns of antiparkinsonian agents in Europe," Movement Disorders, vol. 25, no. 8, pp. 10531060, 2010.

[66] G. Trifirò, R. Savica, L. Morgante et al., "Prescribing pattern of anti-Parkinson drugs in Southern Italy: cross-sectional analysis in the years 2003-2005," Parkinsonism and Related Disorders, vol. 14, no. 5, pp. 420-425, 2008.

[67] E. A. Osinaga, L. C. A. Inchaurregui, I. E. Ikobaltzeta, N. B. Alonso, and J. G. Del Pozo, "A pharmacoepidemiological study of the consumption of antiparkinson drugs in the Basque Autonomous Community (Spain) (1992-2004)," Parkinsonism and Related Disorders, vol. 13, no. 8, pp. 500-504, 2007.

[68] K. Swarztrauber, C. Koudelka, and M. A. Brodsky, "Initial pharmacotherapy in a population of veterans with Parkinson disease," Neurology, vol. 66, no. 9, pp. 1425-1426, 2006.

[69] D. M. Huse, J. Castelli-Haley, L. S. Orsini, G. Lenhart, and J. A. Abdalla, "Patterns of initial pharmacotherapy for Parkinson's disease in the United States," Journal of Geriatric Psychiatry and Neurology, vol. 19, no. 2, pp. 91-97, 2006.

[70] E. K. Tan, A. P. Yeo, V. Tan, R. Pavanni, and M. C. Wong, "Prescribing pattern in Parkinson's disease: are cost and efficacy overriding factors?," International Journal of Clinical Practice, vol. 59, no. 5, pp. 511-514, 2005.

[71] F. Grandas and J. Kulisevsky, "Treatment of Parkinson's disease in Spain," Movement Disorders, vol. 18, no. 1, pp. 87-89, 2003.

[72] H. Askmark, K. Antonov, and S.-M. Aquilonius, "The increased utilisation of dopamine agonists and the 
introduction of COMT inhibitors have not reduced levodopa consumption-a nation-wide perspective in Sweden," Parkinsonism and Related Disorders, vol. 9, no. 5, pp. 271-276, 2003.

[73] O. Leoni, E. Martignoni, M. Cosentino et al., "Drug prescribing patterns in Parkinson's disease: a pharmacoepidemiological survey in a cohort of ambulatory patients," Pharmacoepidemiology and Drug Safety, vol. 11, no. 2, pp. 149-157, 2002.

[74] H. Fukunaga, T. Kasai, and H. Yoshidome, "Clinical findings, status of care, comprehensive quality of life, daily life therapy and treatment at home in patients with Parkinson's disease," European Neurology, vol. 38, no. 2, pp. 64-69, 1997.

[75] F. Menniti-Ippolito, S. Spila-Alegiani, N. Vanacore et al., "Estimate of parkinsonism prevalence through drug prescription histories in the Province of Rome, Italy," Acta Neurologica Scandinavica, vol. 92, no. 1, pp. 49-54, 1995.

[76] W. Chen, S. Chen, Q. Xiao, G. Wang, and S. D. Chen, "Current clinical practice for Parkinson's disease among Chinese physicians, general neurologists and movement disorders specialists: a national survey," BMC Neurology, vol. 12, p. 155, 2012.

[77] M. T. M. Hu, R. Butterworth, V. Kumar et al., "How common and what are the determinants of sub-optimal care for Parkinson's disease patients: the Milton Keynes community study," Parkinsonism and Related Disorders, vol. 17, no. 3, pp. 177-181, 2011.

[78] J. P. Hemming, A. L. Gruber-Baldini, K. E. Anderson et al., "Racial and socioeconomic disparities in parkinsonism," Archives of Neurology, vol. 68, no. 4, pp. 498-503, 2011.

[79] D. Nyholm, E. Karlsson, M. Lundberg, and H. Askmark, "Large differences in levodopa dose requirement in Parkinson's disease: men use higher doses than women," European Journal of Neurology, vol. 17, no. 2, pp. 260-266, 2010.

[80] T. A. Yacoubian, G. Howard, B. Kissela, C. D. Sands, and D. G. Standaert, "Racial differences in Parkinson's disease medication use in the reasons for geographic and racial differences in stroke cohort: a cross-sectional study," Neuroepidemiology, vol. 33, no. 4, pp. 329-334, 2009.

[81] N. Dahodwala, M. Xie, E. Noll, A. Siderowf, and D. S. Mandell, "Treatment disparities in Parkinson's disease," Annals of Neurology, vol. 66, no. 2, pp. 142-145, 2009.

[82] E. M. Cheng, A. D. Siderowf, K. Swarztrauber et al., "Disparities of care in veterans with Parkinson's disease," Parkinsonism and Related Disorders, vol. 14, no. 1, pp. 8-14, 2008.

[83] K. L. Lapane, H. H. Fernandez, J. H. Friedman, and S. Study Group, "Prevalence, clinical characteristics, and pharmacologic treatment of Parkinson's disease in residents in longterm care facilities," Pharmacotherapy, vol. 19, no. 11, pp. 1321-1327, 1999.

[84] O. Skogar, J. Lökk, C.-J. Mats Nilsson, and J. Lokk, "National surveys: a way to manage treatment strategies in Parkinson's disease? Pharmaceutical prescribing patterns and patient experiences of symptom control and their impact on disease," Journal of Multidisciplinary Healthcare, vol. 6, pp. 239-247, 2013.

[85] M. M. Abbas, Z. Xu, and L. C. S. Tan, "Epidemiology of Parkinson's disease-east versus west," Movement Disorders Clinical Practice, vol. 5, no. 1, pp. 14-28, 2018.

[86] T. Pringsheim, N. Jette, A. Frolkis, and T. D. L. Steeves, "The prevalence of Parkinson's disease: a systematic review and meta-analysis," Movement Disorders, vol. 29, no. 13, pp. 1583-1590, 2014.
[87] N. G. Weiskopf and C. Weng, "Methods and dimensions of electronic health record data quality assessment: enabling reuse for clinical research," Journal of the American Medical Informatics Association, vol. 20, no. 1, pp. 144-151, 2013.

[88] E. Herrett, S. L. Thomas, W. M. Schoonen, L. Smeeth, and A. J. Hall, "Validation and validity of diagnoses in the general practice research database: a systematic review," British Journal of Clinical Pharmacology, vol. 69, no. 1, pp. 4-14, 2010.

[89] C. Mytilineou, R. H. Walker, R. JnoBaptiste, and C. W. Olanow, "Levodopa is toxic to dopamine neurons in an in vitro but not an in vivo model of oxidative stress," Journal of Pharmacology and Experimental Therapeutics, vol. 304, no. 2, pp. 792-800, 2003.

[90] J. Jankovic, "Parkinson's disease therapy[colon] tailoring choices for early and late disease, young and old patients," Clinical Neuropharmacology, vol. 23, no. 5, pp. 252-261, 2000.

[91] S. Fahn, D. Oakes, I. Shoulson et al., "Levodopa and the progression of Parkinson's disease," New England Journal of Medicine, vol. 351, no. 24, pp. 2498-2508, 2004.

[92] O. Suchowersky, G. Gronseth, J. Perlmutter, S. Reich, T. Zesiewicz, and W. J. Weiner, "Practice Parameter: neuroprotective strategies and alternative therapies for Parkinson disease (an evidence-based review)," Neurology, vol. 66, no. 7, pp. 976-982, 2006.

[93] C. W. Olanow and J. A. Obeso, "Levodopa toxicity and Parkinson disease: still a need for equipoise," Neurology, vol. 77, no. 15, pp. 1416-1417, 2011.

[94] M. T. Herrero, J. Pagonabarraga, and G. Linazasoro, "Neuroprotective role of dopamine agonists," The Neurologist, vol. 17, no. 1, pp. S54-S66, 2011.

[95] C. V. M. Verschuur, S. R. Suwijn, J. A. Boel et al., "Randomized delayed-start trial of levodopa in Parkinson's disease," New England Journal of Medicine, vol. 380, no. 4, pp. 315-324, 2019.

[96] C. W. Olanow and F. Stocchi, "Levodopa: a new look at an old friend," Movement Disorders, vol. 33, no. 6, pp. 859-866, 2017.

[97] A. H. Schapira, "The clinical relevance of levodopa toxicity in the treatment of Parkinson's disease," Movement Disorders, vol. 23, no. S3, pp. S515-S520, 2008.

[98] T. Foltynie, C. Magee, C. James et al., "Impact of Duodopa on quality of life in advanced Parkinson's disease: a UK case series," Parkinson's Disease, vol. 2013, Article ID 362908, 5 pages, 2013.

[99] A. H. Schapira, "Neuroprotection and dopamine agonists," Neurology, vol. 58, no. 1, pp. S9-S18, 2002.

[100] R. Tintner and J. Jankovic, "Dopamine agonists in Parkinson's disease," Expert Opinion on Investigational Drugs, vol. 12, no. 11, pp. 1803-1820, 2003.

[101] B. M. Ravina, S. C. Fagan, R. G. Hart et al., "Neuroprotective agents for clinical trials in Parkinson's disease: a systematic assessment," Neurology, vol. 60, no. 8, pp. 1234-1240, 2003.

[102] A. H. V. Schapira and C. W. Olanow, "Neuroprotection in Parkinson disease," JAMA, vol. 291, no. 3, pp. 358-364, 2004.

[103] A. H. V. Schapira, "Dopamine agonists and neuroprotection in Parkinson's disease," European Journal of Neurology, vol. 9, no. s3, pp. 7-14, 2002.

[104] A. E. Lang, "When and how should treatment be started in Parkinson disease?," Neurology, vol. 72, no. 2, pp. S39-S43, 2009.

[105] J. J. Ferreira, R. Katzenschlager, B. R. Bloem et al., "Summary of the recommendations of the EFNS/MDS-ES review on 
therapeutic management of Parkinson's disease," European Journal of Neurology, vol. 20, no. 1, pp. 5-15, 2013.

[106] S. H. Fox, R. Katzenschlager, S. Y. Lim et al., "The movement disorder society evidence-based medicine review update: treatments for the motor symptoms of Parkinson's disease," Movement Disorders, vol. 26, no. 3, pp. S2-S41, 2011.

[107] R. Pahwa, S. A. Factor, K. E. Lyons et al., "Practice Parameter: treatment of Parkinson disease with motor fluctuations and dyskinesia (an evidence-based review): [RETIRED]," Neurology, vol. 66, no. 7, pp. 983-995, 2006.

[108] National Institute for Health and Care Excellence, "Parkinson's disease in adults [NG71]," October 2017, https:// tinyurl.com/y8vmwwoa.

[109] M. Yoshioka, K.-i. Tanaka, I. Miyazaki et al., "The dopamine agonist cabergoline provides neuroprotection by activation of the glutathione system and scavenging free radicals," Neuroscience Research, vol. 43, no. 3, pp. 259-267, 2002.

[110] W.-D. Le and J. Jankovic, "Are dopamine receptor agonists neuroprotective in Parkinson's disease?," Drugs and Aging, vol. 18, no. 6, pp. 389-396, 2001.

[111] S. Kaplan and D. Tarsy, "Initial treatment of Parkinson's disease: an update," Current Treatment Options in Neurology, vol. 15, no. 4, pp. 377-384, 2013.

[112] R. Schade, F. Andersohn, S. Suissa, W. Haverkamp, and E. Garbe, "Dopamine agonists and the risk of cardiac-valve regurgitation," New England Journal of Medicine, vol. 356, no. 1, pp. 29-38, 2007.

[113] G. Van Camp, A. Flamez, B. Cosyns, J. Goldstein, C. Perdaens, and D. Schoors, "Heart valvular disease in patients with Parkinson's disease treated with high-dose pergolide," Neurology, vol. 61, no. 6, pp. 859-861, 2003.

[114] J. A. G. Crispo, A. W. Willis, D. P. Thibault et al., "Associations between cardiovascular events and nonergot dopamine agonists in Parkinson's disease," Movement Disorders Clinical Practice, vol. 3, no. 1, pp. 257-267, 2016.

[115] S. Perez-Lloret, M. V. Rey, J. Crispo et al., "Risk of heart failure following treatment with dopamine agonists in Parkinson's disease patients," Expert Opinion on Drug Safety, vol. 13, no. 3, pp. 351-360, 2014.

[116] https://www.fda.gov/Drugs/DrugSafety/ucm319779.htm.

[117] C. Renoux, S. Dell'Aniello, J. M. Brophy, and S. Suissa, "Dopamine agonist use and the risk of heart failure," Pharmacoepidemiology and Drug Safety, vol. 21, no. 1, pp. 34-41, 2012.

[118] M. M. Mokhles, G. Trifirò, J. P. Dieleman et al., "The risk of new onset heart failure associated with dopamine agonist use in Parkinson's disease," Pharmacological Research, vol. 65, no. 3, pp. 358-364, 2012.

[119] https://www.accessdata.fda.gov/drugsatfda_docs/appletter/ 2008/020667s014,020667s017,020667s018ltr.pdf.

[120] D. Weintraub, J. Koester, M. N. Potenza et al., "Impulse control disorders in Parkinson disease: a cross-sectional study of 3090 patients," Archives of Neurology, vol. 67, no. 5, pp. 589-595, 2010.

[121] C. W. Olanow, "Tolcapone and hepatotoxic effects," Archives of Neurology, vol. 57, no. 2, pp. 263-267, 2000.

[122] A. J. Lees, "Comparison of therapeutic effects and mortality data of levodopa and levodopa combined with selegiline in patients with early, mild Parkinson's disease," BMJ, vol. 311, no. 7020, pp. 1602-1607, 1995.

[123] C. W. Olanow, V. V. Myllyla, K. A. Sotaniemi et al., "Effect of selegiline on mortality in patients with Parkinson's disease: a meta-analysis," Neurology, vol. 51, no. 3, pp. 825-830, 1998.
[124] W. W. Danielczyk, "Twenty-five years of amantadine therapy in Parkinson's disease," Journal of Neural Transmission, vol. 46, no. 46, pp. 399-405, 1995.

[125] L. V. Metman, P. Del Dotto, P. van den Munckhof, J. Fang, M. M. Mouradian, and T. N. Chase, "Amantadine as treatment for dyskinesias and motor fluctuations in Parkinson's disease," Neurology, vol. 50, no. 5, pp. 1323-1326, 1998.

[126] A. H. Rajput, A. Rajput, A. E. Lang et al., "Letters to the editor," Movement Disorders, vol. 13, no. 5, pp. 851-854, 1998.

[127] V. Sharma, K. Lyons, and R. Pahwa, "Amantadine extendedrelease capsules for levodopa-induced dyskinesia in patients with Parkinson's disease," Therapeutics and Clinical Risk Management, vol. 14, pp. 665-673, 2018.

[128] J. Jankovic and L. G. Aguilar, "Current approaches to the treatment of Parkinson\&rsquo;s disease," Neuropsychiatric Disease and Treatment, vol. 4, no. 4, pp. 743-757, 2008.

[129] C. Peretz, O. Chillag-Talmor, S. Linn et al., "Parkinson's disease patients first treated at age 75 years or older: a comparative study," Parkinsonism and Related Disorders, vol. 20, no. 1, pp. 69-74, 2014.

[130] S. H. Fox, R. Katzenschlager, S. Y. Lim et al., "International Parkinson and movement disorder society evidence-based medicine review: update on treatments for the motor symptoms of Parkinson's disease," Movement Disorders, vol. 33, no. 8, pp. 1248-1266, 2018.

[131] J. E. Ahlskog, "Seniors with Parkinson's disease: initial medical treatment," Journal of Clinical Neurology, vol. 6, no. 4, pp. 159-166, 2010.

[132] R. G. Holloway, I. Shoulson, S. Fahn et al., "Pramipexole vs levodopa as initial treatment for Parkinson disease: a 4-year randomized controlled trial," Archives of Neurology, vol. 61, no. 7, pp. 1044-1053, 2004.

[133] A. L. Whone, R. L. Watts, A. J. Stoessl et al., "Slower progression of Parkinson's disease with ropinirole versus levodopa: the REAL-PET study," Annals of Neurology, vol. 54, no. 1, pp. 93-101, 2003.

[134] J. Zhang and L. Chew-Seng Tan, "Revisiting the medical management of Parkinson's disease: levodopa versus dopamine agonist," Current Neuropharmacology, vol. 14, no. 4, pp. 356-363, 2016.

[135] K. J. Klos, J. H. Bower, K. A. Josephs, J. Y. Matsumoto, and J. E. Ahlskog, "Pathological hypersexuality predominantly linked to adjuvant dopamine agonist therapy in Parkinson's disease and multiple system atrophy," Parkinsonism and Related Disorders, vol. 11, no. 6, pp. 381-386, 2005.

[136] M. Contin, R. Riva, P. Martinelli, F. Albani, and A. Baruzzi, "Effect of age on the pharmacokinetics of oral levodopa in patients with Parkinson's disease," European Journal of Clinical Pharmacology, vol. 41, no. 5, pp. 463-466, 1991.

[137] D. Robertson, N. Wood, H. Everest et al., "The effect of age on the pharmacokinetics of levodopa administered alone and in the presence of carbidopa," British Journal of Clinical Pharmacology, vol. 28, no. 1, pp. 61-69, 1989.

[138] M. Horstink, E. Tolosa, U. Bonuccelli et al., "Review of the therapeutic management of Parkinson's disease. Report of a joint task force of the European federation of neurological societies and the movement disorder Society?European section. Part I: early (uncomplicated) Parkinson's disease," European Journal of Neurology, vol. 13, no. 11, pp. 1170-1185, 2006.

[139] A. W. Willis, M. Schootman, N. Kung, X.-Y. Wang, J. S. Perlmutter, and B. A. Racette, "Disparities in deep brain 
stimulation surgery among insured elders with Parkinson disease," Neurology, vol. 82, no. 2, pp. 163-171, 2014.

[140] E. N. Eskandar, A. Flaherty, G. R. Cosgrove, L. A. Shinobu, and F. G. Barker, "Surgery for Parkinson disease in the United States, 1996 to 2000: practice patterns, short-term outcomes, and hospital charges in a nationwide sample," Journal of Neurosurgery, vol. 99, no. 5, pp. 863-871, 2003.

[141] J. J. Cohen, "Disparities in health care: an overview," Academic Emergency Medicine, vol. 10, no. 11, pp. 1155-1160, 2003.

[142] A. Park and M. Stacy, "Non-motor symptoms in Parkinson's disease," Journal of Neurology, vol. 256, no. 3, pp. 293-298, 2009.

[143] J. E. Ahlskog, Parkinson's Disease Treatment Guide for Physicians, Oxford University Press, Oxford, UK, 2009.

[144] P. Midlöv, Å. Bondesson, T. Eriksson, J. Petersson, L. Minthon, and P. Höglund, "Descriptive study and pharmacotherapeutic intervention in patients with epilepsy or Parkinson's disease at nursing homes in southern Sweden," European Journal of Clinical Pharmacology, vol. 57, no. 12, pp. 903-910, 2002.

[145] N. J. Weerkamp, G. Tissingh, P. J. E. Poels et al., "Parkinson disease in long term care facilities: a review of the literature," Journal of the American Medical Directors Association, vol. 15, no. 2, pp. 90-94, 2014

[146] R. B. Schneider and K. M. Biglan, "The promise of telemedicine for chronic neurological disorders: the example of Parkinson's disease," The Lancet Neurology, vol. 16, no. 7, pp. 541-551, 2017.

[147] O. Egunsola, I. Choonara, and H. M. Sammons, "Anti-epileptic drug utilisation in paediatrics: a systematic review," BMJ Paediatrics Open, vol. 1, no. 1, Article ID e000088, 2017.

[148] A. Rossignoli, A. Clavenna, and M. Bonati, "Antibiotic prescription and prevalence rate in the outpatient paediatric population: analysis of surveys published during 2000-2005," European Journal of Clinical Pharmacology, vol. 63, no. 12, pp. 1099-1106, 2007. 


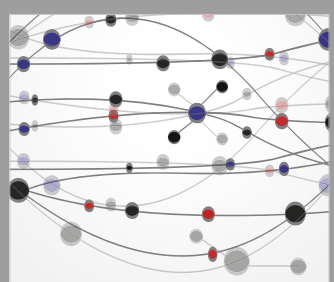

The Scientific World Journal
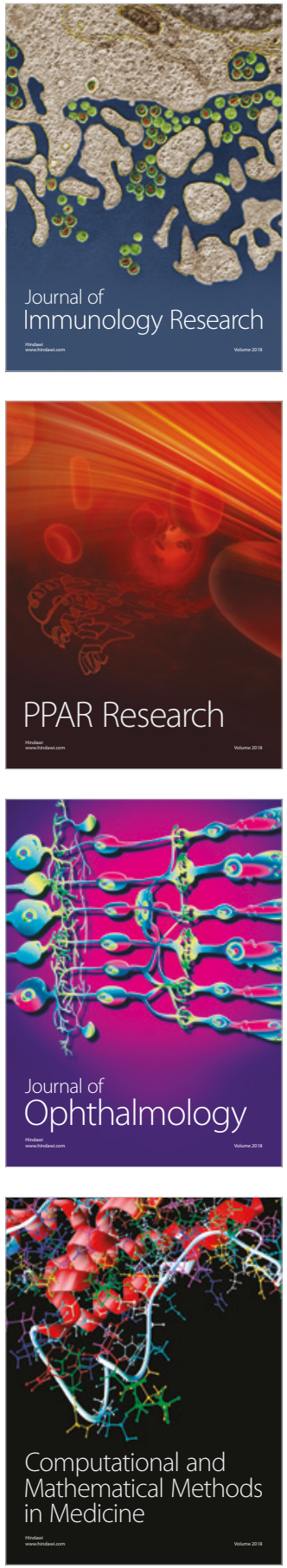

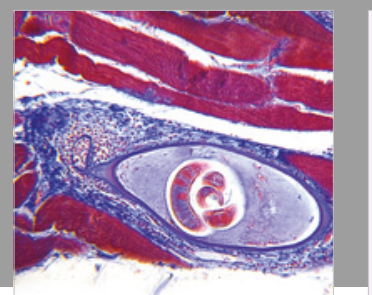

Gastroenterology Research and Practice

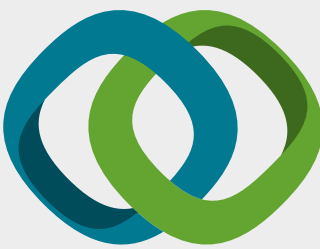

\section{Hindawi}

Submit your manuscripts at

www.hindawi.com
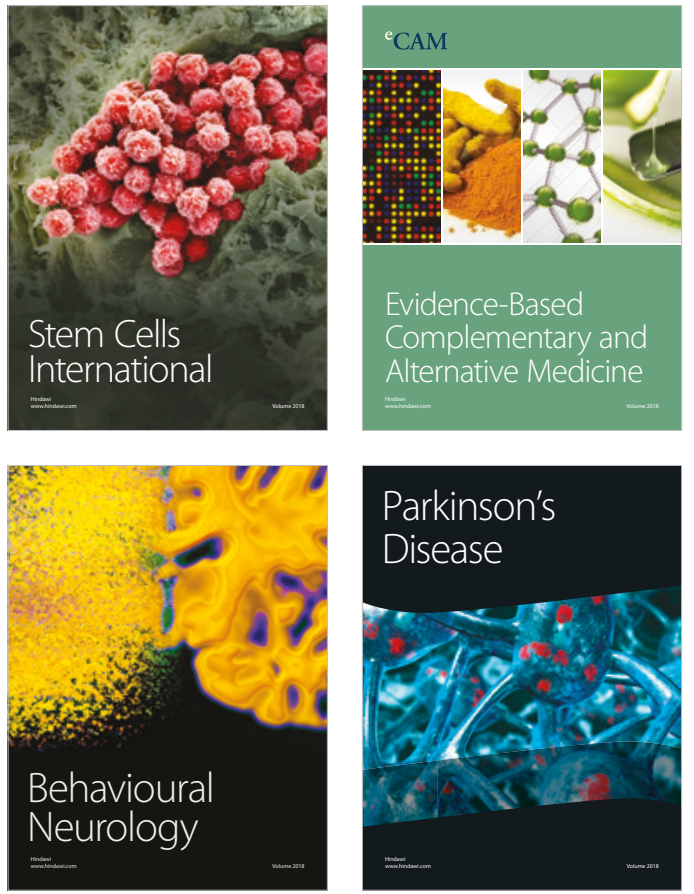

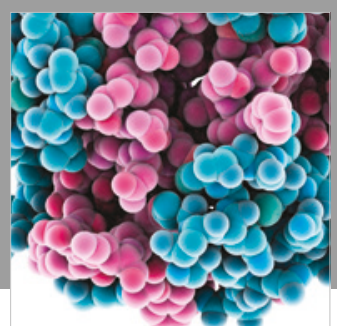

ournal of

Diabetes Research

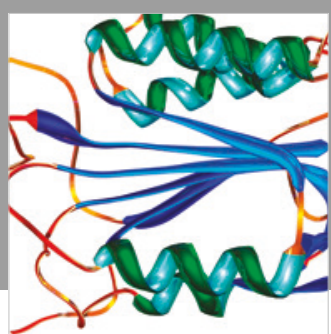

Disease Markers
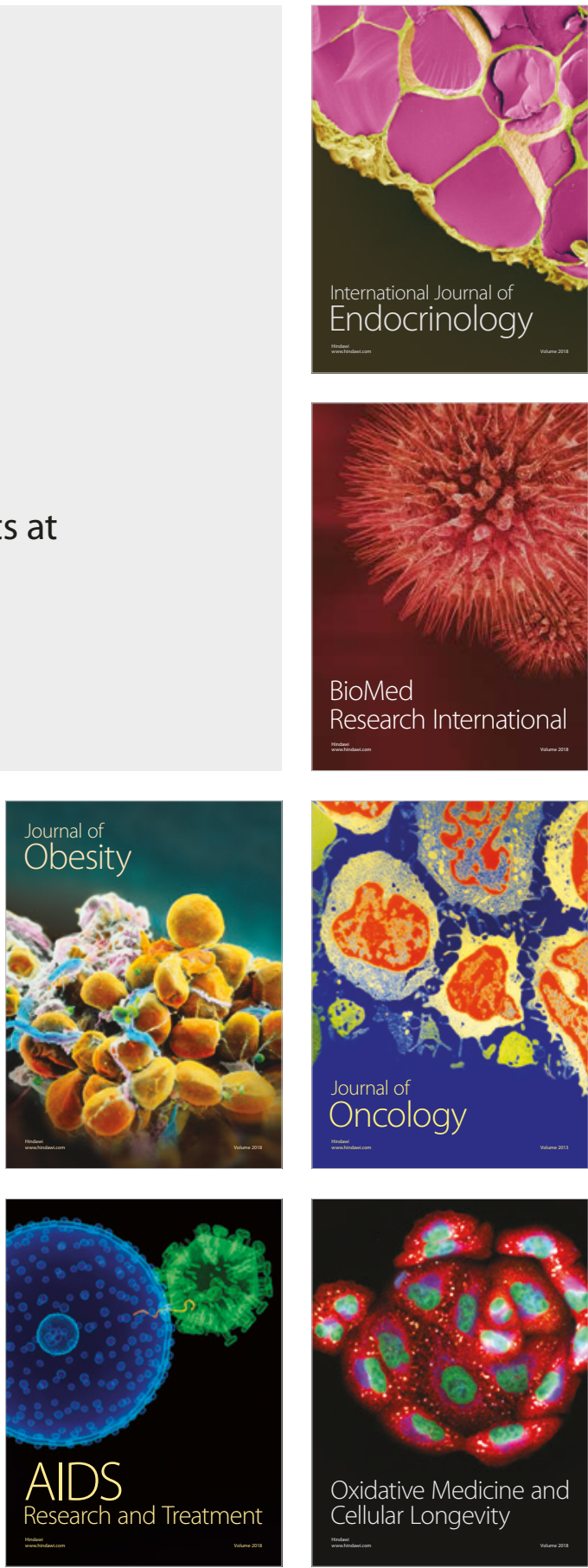